\title{
Validating Resilience and Vulnerability Indices in the Context of Natural Disasters
}

\author{
Laura A. Bakkensen ${ }^{1}$, Cate Fox-Lent ${ }^{2}$, Laura Read ${ }^{2}$, and Igor Linkov²
}

\footnotetext{
${ }^{1}$ University of Arizona, School of Government and Public Policy, 315 Social Science Bldg., Tucson, AZ 85721, USA. LauraBakkensen@email.arizona.edu.

${ }^{2}$ US Army Corps of Engineers, Engineer Research \& Development Center, 696 Virginia Road, Concord, MA 01742, USA. Catherine.Fox-Lent@usace.army.mil; laura.read@tufts.edu; Igor.Linkov@usace.army.mil
} 


\begin{abstract}
Due to persistent and serious threats from natural disasters around the globe, many have turned to resilience and vulnerability research to guide disaster preparation, recovery, and adaptation decisions. In response, scholars and practitioners have put forth a variety of disaster indices, based on quantifiable metrics, to gauge levels of resilience and vulnerability. However, few indices are empirically validated using observed disaster impacts and, as a result, it is often unclear which index should be preferred for each decision at hand. Thus, we compare and empirically validate five of the top U.S. disaster indices, including three resilience indices and two vulnerability indices. We use observed disaster losses, fatalities, and disaster declarations from the southeastern United States to empirically validate each index. We find that disaster indices, though thoughtfully substantiated by literature and theoretically persuasive, are not all created equal. While four of the five indices perform as predicted in explaining damages, only three explain fatalities and only two explain disaster declarations as expected by theory. These results highlight the need for disaster indices to clearly state index objectives and structure underlying metrics to support validation of the results based on these goals. Further, policy makers should use index results carefully when developing regional policy or investing in resilience and vulnerability improvement projects.
\end{abstract}

Keywords: Resilience and Vulnerability, Index, Natural Disaster 


\section{INTRODUCTION}

Natural disasters cause destruction and threaten livelihoods, economic activity, and cultures in every country across the globe. In addition to these economic losses, natural disasters lead to injury and loss of life, destruction of environmental quality, psychological harm, as well as indirect losses. ${ }^{(1-5)}$ These major disruptions are huge shocks to human, social, economic, and environmental systems.

Despite risk management actions to lessen impacts, losses have increased over time ${ }^{(6)}$, motivating a new resilience management paradigm as a policy objective in the U.S. and worldwide. Two recent U.S. Executive Orders focus on improving the understanding of resilience. ${ }^{(7,8)}$ The U.S. Department of Housing and Urban Development launched a $\$ 1$ billion initiative to increase natural disaster resilience across communities. ${ }^{(9)}$ In the wake of the 2013 Typhoon Yolanda, the Philippine government launched Reconstruction Assistance in Yolanda, an \$8.2 billion plan to recover from the detrimental storm and increase resilience. ${ }^{(10)}$ Other examples are found in the United Kingdom's National Resilience Capabilities Programme, Canada's National Disaster Mitigation Strategy, and the Dominican Republic's National Plan for Comprehensive Disaster Risk Management ${ }^{(44-46)}$. Thus, resilience and vulnerability to natural disasters remains an important policy objective across many governments. But how can governments quantify the impacts of the billions of public dollars spent? And how can policy makers know which areas to target for improvements?

In response to the clear need for disaster research, academics and practitioners alike have come conducted many studies in an effort to better understand resilience and vulnerability. One major focus has been the development of indices to quantify resilience and vulnerability using metrics. In a recent United Nations review, 27 such indices were identified with spatial scales from community to country level. Disaster indices are generated for multiple purposes and therefore may exhibit significantly different performance across disaster outcomes and resilience objectives. While all have been motivated by rich theory, few measurement frameworks have been empirically verified. ${ }^{(11)}$ Although community resilience to disasters is still an emerging field and index developers often describe their products as frameworks or baseline assessments, there is little utility unless they can be confidently used to inform decision makers. 
This work contributes to the field in several ways. First, we review and compare the results of five prominent disaster indices in the United States: Cutter, Burton, and Emrich's ${ }^{(12)}$ Baseline Resilience Index for Communities (BRIC); Peacock et al.'s ${ }^{(13)}$ Community Disaster Resilience Index (CDRI); Foster's ${ }^{(14)}$ Resilience Capacity Index (RCI) as applied to metropolitan areas by the Network on Building Resilient Regions ${ }^{(15)}$; Cutter, Boruff, and Shirley's ${ }^{(16)}$ Social Vulnerability Index (SoVI); and Flanagan et al.'s ${ }^{(17)}$ Social Vulnerability Index (SVI). We then empirically validate each index to test their power to explain historical property losses, fatalities, and disaster declarations at the county-event level across states in the Southeast. We compare the results with the stated index objectives, to examine the relevance of each index and to identify best practices for index development to support further validation. Finally, we offer policy recommendations based on our findings, to enable disaster indices to be better utilized to inform policy and action.

\section{BACKGROUND}

\subsection{Defining Resilience and Vulnerability}

Early concepts of resilience focused on how well a system could rebound or reorganize to re-establish stability following a stress or perturbation, especially in ecological systems, engineered materials, and individual psychology. ${ }^{(18-20)}$ More recently, social scientists have adopted the concept and applied it at a broader scale for human communities with respect to disasters. The magnitude of natural disaster impacts is a function of both natural and human factors $^{(21)}$ and thus resilience to disasters often considers inputs from factors in both domains. Disaster resilience also occurs on multiple actor scales including individual, governmental, and private market ${ }^{(22)}$, and across multiple disciplines or community sub-systems, such as economic, social, infrastructural, and institutional networks. ${ }^{(12)}$ While there is no universal definition of the term $^{(23)}$, resilience implies that a system can persist and function more successfully over the duration of an event, relative to a less-resilient counterpart. These key elements are highlighted in two definitions, including the National Academy of Science's definition of disaster resilience as "the ability to prepare and plan for, absorb, recover from, and more successfully adapt to adverse events" and the Intergovernmental Panel on Climate Change's definition of "the ability of a system and its component parts to anticipate, absorb, accommodate or recover from the effects of a hazardous event in a timely and efficient manner, including through ensuring the preservation, restoration or improvement of its essential basic structures and functions". (24-26) 
Similar to resilience, vulnerability is a concept used to inform organizations and governments on the susceptibility of a system to a specific threat. Vulnerability is a component of the risk formula: risk = hazard $\mathrm{x}$ vulnerability $\mathrm{x}$ consequence, but has multiple working definitions across domains. Adger ${ }^{(27)}$ relates vulnerability to exposure and sensitivity to stresses as well as the capacity to adapt. Linkov et al. ${ }^{(28)}$ conceptualize vulnerability as a factor in system risk or the maximum losses at one point in time, whereas resilience represents the integral across all disaster time steps, including recovery and adaptation. Social vulnerability is an important component to overall vulnerability, but research on social vulnerability has trailed other concepts due to the difficulty in quantifying the concept. ${ }^{(16)}$ Cutter, Boruff, and Shirley define vulnerability to natural disasters as the "potential for loss" across space and time. ${ }^{(16)}$ Put differently, groups exposed to the same hazard may suffer very different impacts due to differing levels of social vulnerability. ${ }^{(17)}$ Some conceptualize vulnerability as the opposite of resilience or that vulnerability encompasses resilience. Others view vulnerability as a related, but not opposite term, as vulnerability is a temporary shift in functional states, whereas resilience encompasses broader changes in the structural system or overall system stability. ${ }^{(29)}$

\subsection{Quantifying Resilience and Vulnerability}

Measuring resilience and vulnerability to natural disasters is a rapidly emerging area of literature. One approach to quantification is an index, or "composite indicator", that aggregates metrics across a variety of numerical factors in order to gauge the level of disaster resilience or vulnerability across space. Cutter (2015) reviews the assortment of tools, indicators, and

scorecards that currently populate the resilience literature in the United States. ${ }^{(64)}$ The policy relevance of an index relies on its ability to pinpoint areas in need of improvement. Although social vulnerability and resilience may be different theoretical constructs, popular indices of vulnerability have stated goals of identifying "uneven capacity for preparedness and response and... determining differential recovery from disasters" and informing management across "all phases of the disaster cycle", which closely match the definition of, and goals of, resilience indices. ${ }^{(30,17)}$

For community disaster resilience and social vulnerability indices, metrics are chosen to fit a number of relevant sub-system categories, including human and social capital, infrastructure, economic capital, and institutional organization, or to fit the stages of a disruptive event, e.g. prepare, absorb, recover, and adapt. Most prominent community disaster vulnerability and 
resilience indices in the U.S. have selected metrics that are widely collected and readily available through the Census Bureau, Federal Emergency Management Agency, and other federal agencies. The value of these metrics are their consistent collection methodology, public availability, and frequency of collection, allowing for the monitoring of changes over time. However, as we show below, although many indices draw on similar sets of metrics, the results vary from index to index. These disparities highlight the critical influence of the specific set of metrics selected and the method of aggregation and normalization. With many indices to choose from, all with stated purposes of assessing resilience or vulnerability in general, and with disparate resulting resilience and vulnerability rankings, it can be difficult for policy makers to understand and select the appropriate index to inform decision making and guide investment in resilience improvement.

Index validation is an important final step in index creation, but is rarely performed. ${ }^{(11)}$ Many resilience indices rely on a meta-analysis of the literature and theoretical justifications to create indices, which are not the same as empirical validation. While theoretical and meta-analysis index justifications are important in setting indices within the existing knowledge base, they do not guarantee that the metrics selected will meaningfully relate to specific outcomes of interest. Empirical validation, on the other hand, assesses the explanatory power of an index using real world observations and can estimate the ability of an index to explain a variety of disaster losses, thereby giving confidence in index ability and performance to end users. Two important efforts of validation are noted: Burton ${ }^{(31)}$ tests his resilience index by visual ranking of recovery photographs before and after Hurricane Katrina, and Peacock et al. ${ }^{(13)}$ validate their resilience matrix using disaster losses and fatalities. However, no research has compared performance across different index approaches or analyzed the differential results across disaster indices.

\section{REVIEW OF DISASTER INDICES}

In this paper, we analyze the performance of five prominent disaster resilience and vulnerability indices in the United States. While many disaster resilience indices exist, we selected indices for this analysis based on the following criterion: 1) an index based in the United States at the county-level (or similar size such as a metropolitan statistical area or census track) that includes observations in the Southeastern United States, 2) analyzing resilience or vulnerability to natural disasters, 3) with data publically available on the final index score. The five indices selected are: Cutter, Burton, and Emrich's Baseline Resilience Index for Communities (BRIC); Peacock et al.'s 
Community Disaster Resilience Index (CDRI); Foster's Resilience Capacity Index (RCI); Cutter, Boruff, and Shirley's Social Vulnerability Index (SoVI); and Flanagan et al.'s Social Vulnerability Index (SVI). ${ }^{(12-17)}$ These indices have assessed by others, used as a basis to build upon, applied in case studies, and added to toolkits for federal and international agencies [BRIC ${ }^{(56,57,58)}{ }^{\text {, CDRI }}{ }^{(53,}$ $\left.{ }^{54,55)}, \mathrm{RCI}^{(24,51,52)}, \mathrm{SOVI}^{(59,60,61)}, \mathrm{SVI}^{(61,62,63)}\right]$. In this section, we describe each index in detail and provide a comparison of the stated performance.

\subsection{Baseline Resilience Index for Communities}

The resilience index of Cutter et al. ${ }^{(12)}$ is one of the first, and more widely cited, indices in the resilience literature in its attempt to quantify resilience. The Baseline Resilience Index for Communities (BRIC) approach has the stated purpose of providing a "baseline set of conditions, from which to measure the effectiveness of programs, policies, and interventions specifically designed to improve disaster resilience". ${ }^{(12)}$ BRIC is intended to quantify resilience across space and can be re-calculated over time to track changes in this baseline level of resilience. After a metrics selection process using theory and analysis of the inter-metric correlations and internal reliability, 36 metrics remain across five resilience categories: social, economic, institutional, infrastructure, and community. To form the final index score, each metric is normalized through a min-max algorithm that subtracts the minimum value across the observations and divides by the maximum value. Therefore, the scores are inherently relative to the sample of interest. Finally, metric scores across each category are averaged and the categories summed to generate the final index score between 0 (least resilient) and 5 (most resilient). The method is applied to 736 counties in FEMA Region IV including most of the Southeastern United States. Data are typically from the year 2000, although a few metrics are later, from 2006 or 2007. Figure 1 maps each county included in BRIC by the index magnitude. The counties are color coded based on the resilience quantile. Generally, this approach finds urban areas and coastal regions to have higher resilience, relative to inland or rural areas. While this approach is well justified through theoretical and statistical means in the metric selection phase, it is not empirically validated. ${ }^{(12)}$ We also acknowledge that Cutter and coauthors recently released an updated index that includes additional metrics, but follows the same categorically-based methodology. ${ }^{(32)} \mathrm{We}$ were unable to access the revised 2014 county-level index data, so we have not included the results in this analysis. 


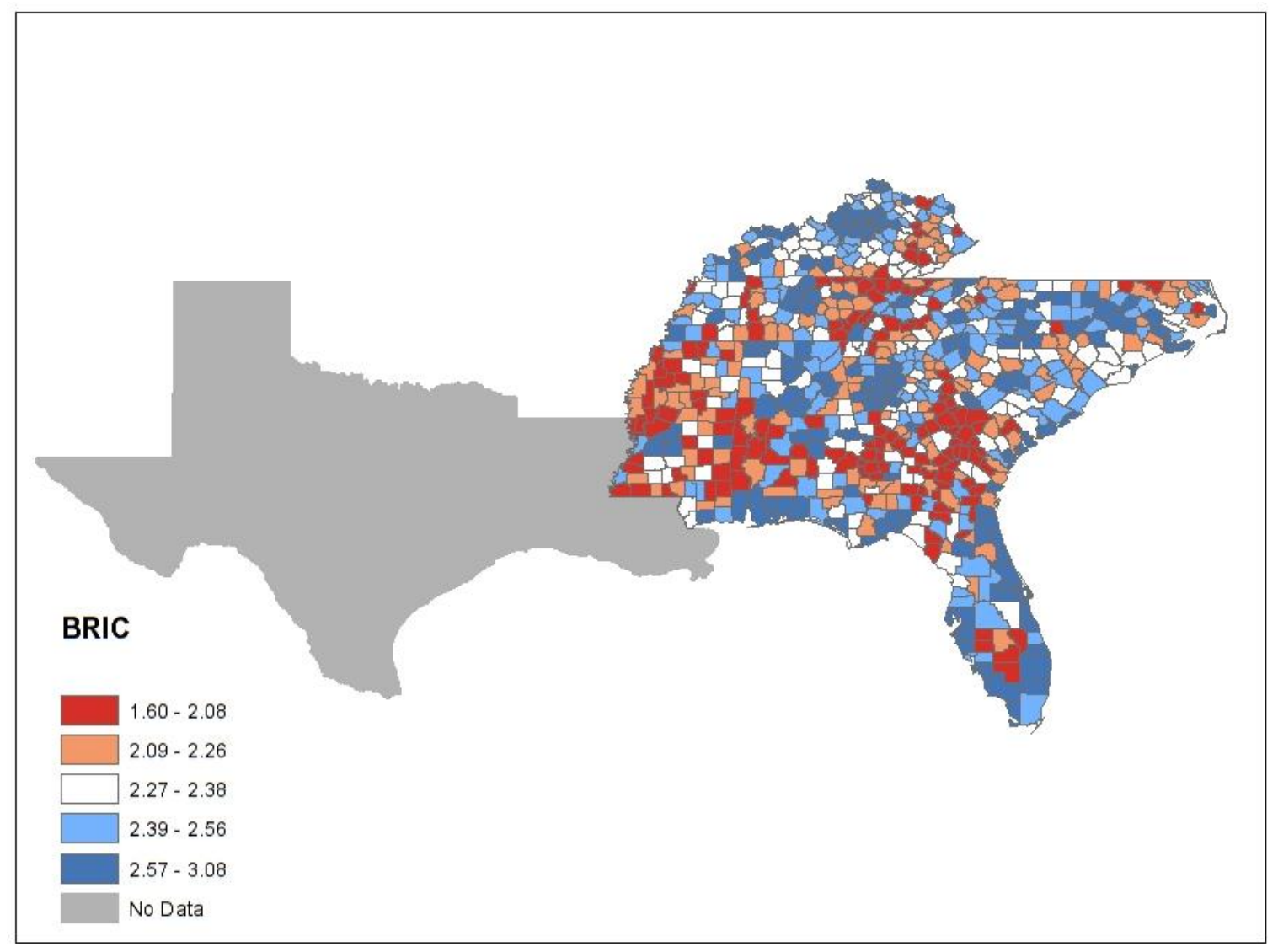

Figure 1: Baseline Resilience Index for Communities (BRIC) counties by index magnitude. Red indicates low resilience, blue indicates high resilience, and grey represents counties not included in the scope of BRIC.

\subsection{Community Disaster Resilience Index}

Peacock et al.'s ${ }^{(13)}$ Community Disaster Resilience Index (CDRI) is a joint effort between researchers across multiple academic and research institutions in Texas. The stated goal is to develop a "comprehensive measure of community disaster resilience". ${ }^{(13)}$ Unlike the BRIC approach, the CDRI uses a matrix approach, placing metrics in categories (or "Capital Domains"): social, economic, physical, and human; as well as temporal steps (or "Disaster Phases"): mitigation, preparedness, response, and recovery. Metrics are chosen from an initial list of 120 variables classified across the 16 disaster phase-capital matrix cells. Next, alpha analysis is used to screen each metric within a matrix cell, in order to select 75 indicators that maximized the alpha value using the fewest variables within each cell. While the BRIC approach places each metric in a single category, metrics in CDRI are allowed to impact multiple disaster phases. To calculate the 
final index score, individual metric scores are z-normalized to center the average value at zero and then averaged within each categorical grouping and then averaged, again, across the four categories. The method is applied to 144 coastal and near-coastal counties across the Gulf Coast using data from 2000 to 2005 . The resulting index ranges from -1.317 (least resilient) to 1.436 (most resilient). Results from the CDRI are mapped in Figure 2. CDRI finds that much of coastal Florida and urban areas including Houston, TX and Mobile, AL are more resilient, relative to poorer urban areas in southern Texas and Louisiana. The CDRI is unique in that the authors provide empirical validation of the index, running both correlation analysis with the CDRI index and relevant outcomes such as observed damages, fatalities, vulnerability, and the underlying physical risk. In addition, they use regression analysis to control for additional factors when predicting property damage and fatalities. The authors find that the index performs as expected in all cases, except for the probability (but not number) of fatalities.

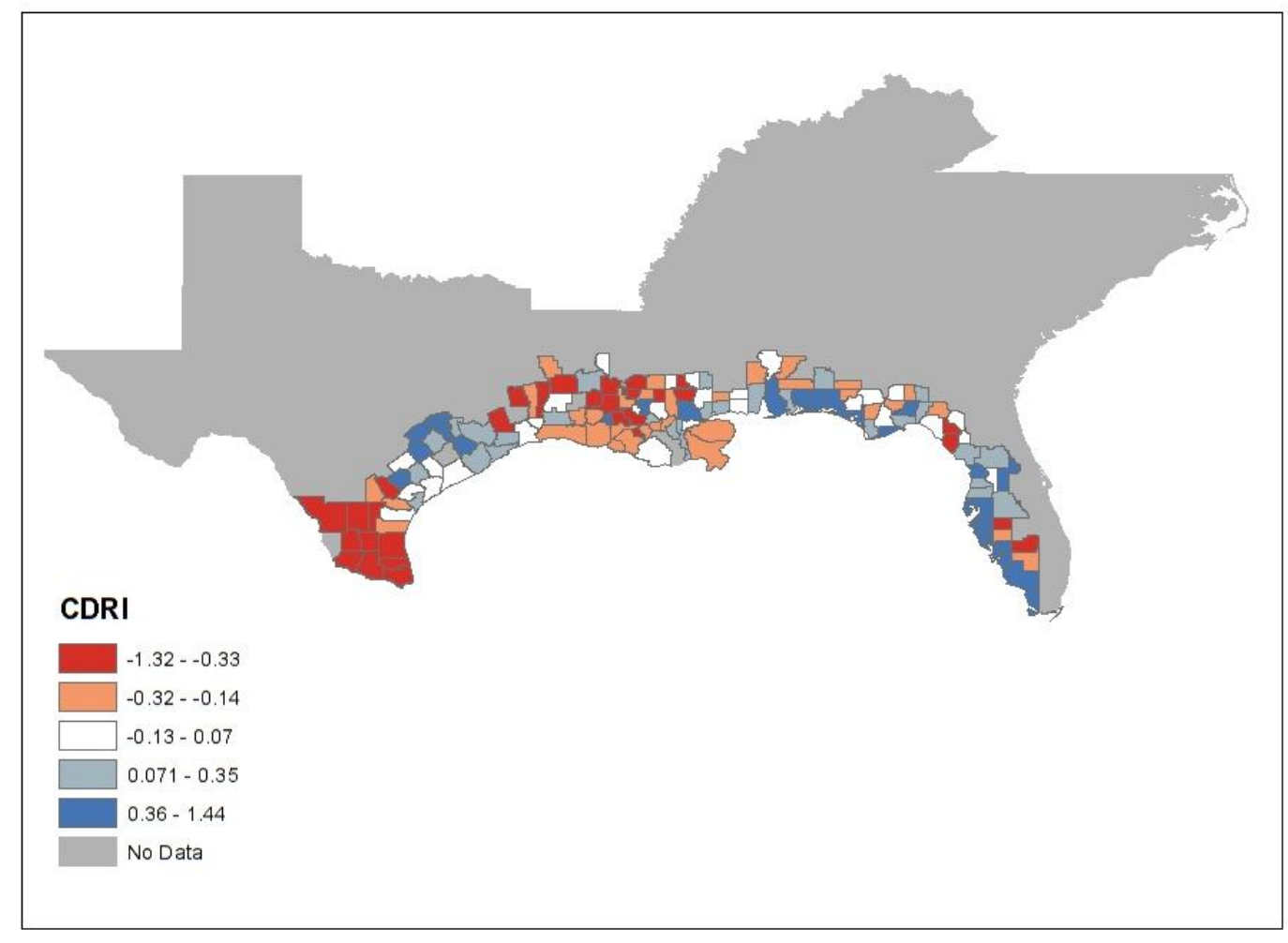

Figure 2: Community Disaster Resilience Index (CDRI) by index magnitude. Red indicates low resilience; blue indicates high resilience, and grey represents counties not included in the scope of CDRI. 


\subsection{Resilience Capacity Index}

Foster's ${ }^{(14)}$ Resilience Capacity Index (RCI) has a broader scope than just natural disasters, encompassing additional stresses such as economic shocks such as major factories closing or long term population growth or economic downturns. RCI was created to measure the "resilience capacity", or the pre-disaster resilience level as an indicator of the potential performance of a location under stress. While higher resilience in the RCI is not deterministic in outcomes, "[h]aving higher capacity does imply, however, that the region has factors and conditions thought to position a region well for effective post-stress resilience performance."(15) Another key difference with the RCI compared with the other indices is that the RCI quantifies resilience at the metropolitan area level, not the county level, with 361 metropolitan areas included. The RCI is the most parsimonious, with only 12 metrics spread across three categories (“capacities"): regional economic, socio-demographic, and community connectivity. Each metric is z-normalized based on values observed across the data and then all 12 scores are averaged to produce the final RCI score. Scores range from -1.66 (least resilience) to 1.23 (most resilient), using data from 2009 to 2010. Figure 3 displays the resilience quantification of the RCI. Since the scores are normalized relative to all metropolitan areas across the country, a majority of Southeastern cities fall in the bottom half of the distribution, with medium (parts of Florida and the Carolinas) to low and very low levels (many urban areas in Texas, Louisiana, and Georgia) of resilience capacity. Empirical validation is not addressed, but "resilience performance" is discussed using comparisons with data on GDP and employment recovery following a shock. ${ }^{(14)}$ 


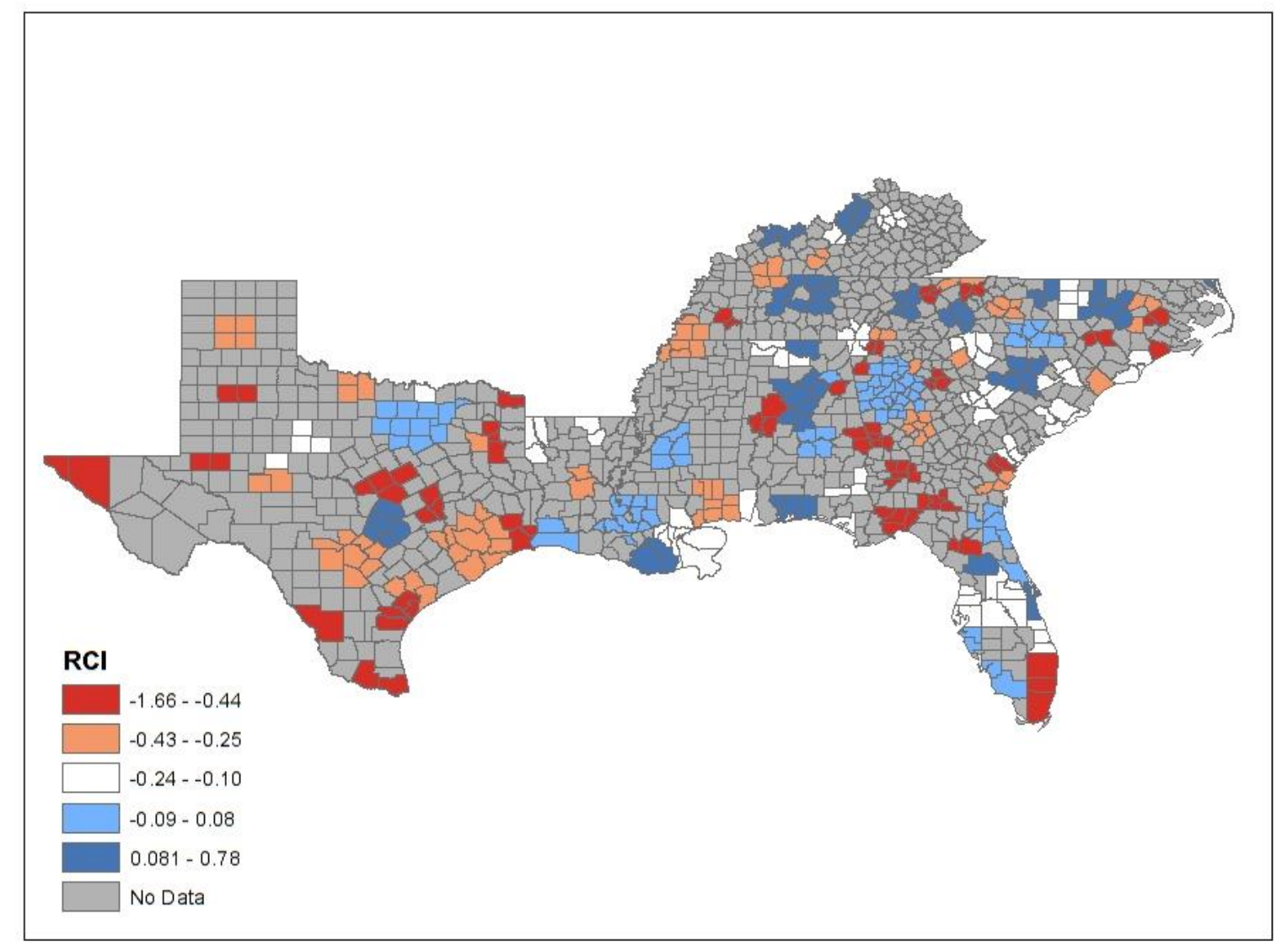

Figure 3: Resilience Capacity Index (RCI) counties by index magnitude. Red indicates low resilience, blue indicates high resilience, grey represents counties not included in the scope of RCI.

\subsection{Social Vulnerability Index (SoVI)}

Cutter, Boruff, and Shirley's ${ }^{(16)}$ Social Vulnerability Index (SoVI) is one of the original approaches to quantifying social vulnerability to environmental disasters and hazards and is relevant to resilience work in that it is a "...tool for policy makers and practitioners [as] it shows where there is uneven capacity for preparedness and response and... is useful as an indicator in determining differential recovery from disasters". ${ }^{(33)}$ Originally based on the Hazards-of-Place model $^{(34)}$, factor analysis is employed to whittle 42 vulnerability variables down to 11 normalized factors explaining vulnerability. Scores are calculated by summing the raw metrics for each county across the United States using 1990 data and have been re-run in 2000, 2005-2009, and 2006-2010. The SoVI has evolved; the 2006-2010 SoVI includes 10 factors instead of 11, as new vulnerability research has shed light on different factors. ${ }^{(33)}$ Unlike for resilience, a high SoVI score represents high vulnerability (such as in parts of southern Texas, along the Mississippi river, and in the rural 
South). A low SoVI score represents low vulnerability (such as in urban and coastal areas across the Southeast). Figure 4 displays the results of the SoVI quantification scheme. "To test the reliability and usefulness of the SoVI", the SoVI 1990 results were correlated with the frequency of disaster declarations. ${ }^{(16)}$ The relationship was weak but negatively correlated, indicating that more vulnerable counties have fewer disaster declarations in opposition to the expected relationship.

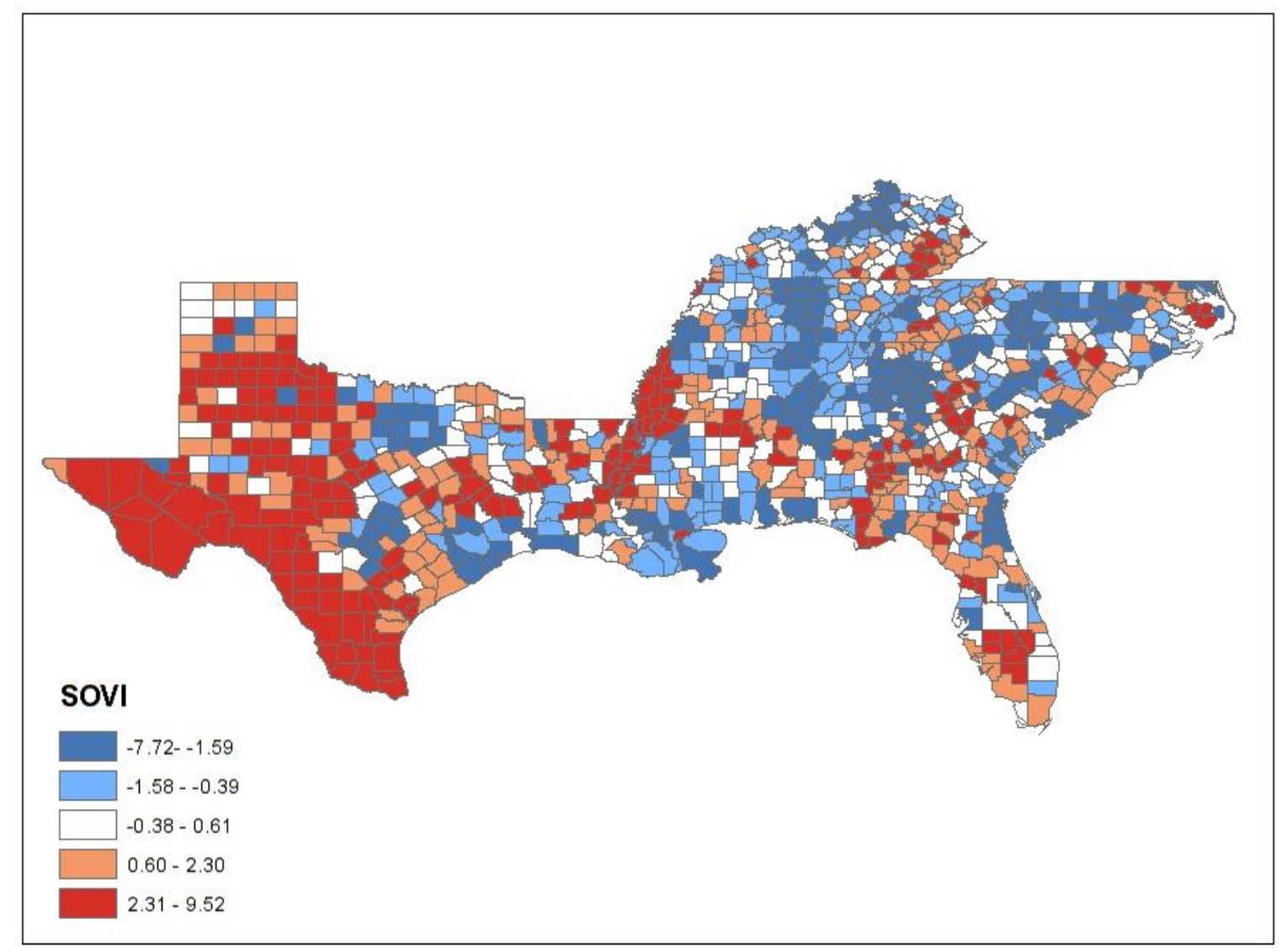

Figure 4: Social Vulnerability Index (SoVI) counties by index magnitude. Red indicates low resilience, blue indicates high resilience, and grey represents counties not included in the scope of SoVI.

\subsection{Social Vulnerability Index (SVI)}

Flanagan et al.'s ${ }^{(17)}$ Social Vulnerability Index (SVI) quantifies social vulnerability to disasters. The SVI's motivation is to aid in disaster management from a social perspective, with the stated goal of "improving all phases of the disaster cycle: mitigation, preparedness, response, and recovery"(17), which again mimics the key ideas of resilience and uses similar metrics to the 
resilience indices (Table I). The SVI places 15 census variables in the following four social vulnerability categories: socioeconomic status, household composition and disability, minority status and language, and housing and transportation. The data collection scale is different than the previous indices: the SVI data were collected at the census track level from the 2000 Census, rather than the county level. Census track level percentile ranks by metric were calculated to show the relative value of a location within the United States. Finally, percentile ranks were added across all 15 variables for each census track, resulting in a score between 0 (least vulnerable) to 15 (most vulnerable). Figure 5 maps the results of the SVI. Broadly, the SVI finds higher vulnerability in the Mississippi river region as well as rural areas in the Southeast. While they do not provide a full empirical validation, the SVI is mapped along with Hurricane Katrina outcomes, including number of drowning deaths (an indicator of disaster impact) and percent of individuals restarting their mail service (an indicator of recovery). While there is visual agreement, the authors note that do not have sufficient data to perform a quantitative analysis.

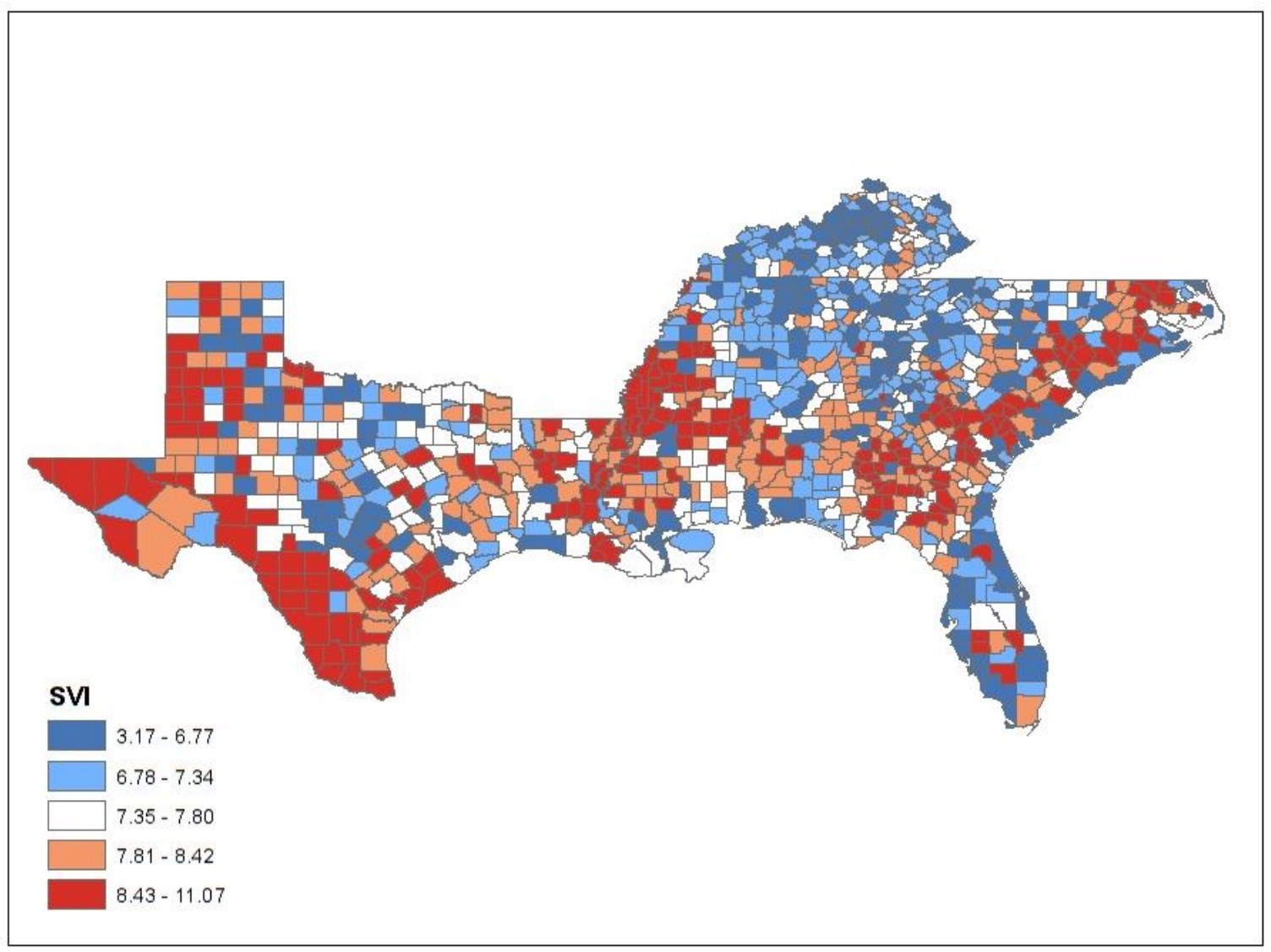


Figure 5: Social Vulnerability Index (SVI) counties by index magnitude. Red indicates low resilience, blue indicates high resilience, and grey represents counties not included in the scope of SVI.

\subsection{Comparison of Indices}

The five indices selected for this study include two social vulnerability indices and three disaster resilience indices. All have the goal of describing the general ability of a community to persevere through a disruptive event and most try to capture the robustness of the physical infrastructure, business community, and residents. None focus on a specific community function (such as providing and maintaining transportation, housing, or medical services) and so all use aggregation schemes that weight individual metrics, or categories of metrics, equally. Table I identifies specific metrics that are common across two or more the indices. Yet, despite the similarities, the index results are not as consistent. Figure 6 shows the relative resilience (as reported by the indices' authors) for three sets of adjacent counties. For Figure 6 only, vulnerability scores were inverted (e.g., a score of 1 , meaning not vulnerable, is displayed as a 5, very resilient) for ease of comparison in the figure. These regions were selected from the available areas of overlap among the indices and represent three sections of the Gulf Coast, with a mix of urban, suburban, and rural areas. While there are some similar results, overall, there is not consistent agreement on the overall magnitude of resilience in a county or on the pattern of resilience across a multi-county region. In general, the CDRI and BRIC report higher capacity for these regions than do the vulnerability indices and the RCI results in the lowest capacity. 
Table I: Selected Metrics Underlying Disaster Indices

\begin{tabular}{|c|c|c|c|c|c|}
\hline Metric & BRIC & CDRI & $\mathbf{R C l}$ & SOVI & SVI \\
\hline Total number of metrics in index: & 36 & 75 & 12 & 11 & 15 \\
\hline \multicolumn{6}{|l|}{ Metrics in common with other indices: } \\
\hline Gini Coefficient of inequality & $x$ & & $x$ & & \\
\hline $\begin{array}{l}\text { Education level (ratio of college degrees to no-high } \\
\text { school diploma) }\end{array}$ & $x$ & $x$ & $x$ & $x$ & $x$ \\
\hline Population with/without disability & $x$ & & $x$ & & $x$ \\
\hline Poverty rate & & & $\mathrm{x}$ & $\mathrm{x}$ & $x$ \\
\hline Rate of health insurance & $x$ & $x$ & $x$ & $x$ & \\
\hline Density of civic organizations & $x$ & $x$ & $x$ & & \\
\hline Rates of homeownership / owner-occupied units & $x$ & $x$ & $x$ & & \\
\hline Per capita income & & $x$ & & $x$ & $x$ \\
\hline Unemployment rate & $x$ & $x$ & & $x$ & $x$ \\
\hline Median home value & & $x$ & & $x$ & \\
\hline Occupied versus vacant housing units & & $x$ & & $x$ & \\
\hline Physical infrastructure density (schools, hospitals, etc) & $\mathrm{x}$ & $x$ & & & \\
\hline Access to vehicle & $\mathrm{x}$ & $x$ & & $\mathrm{x}$ & $x$ \\
\hline Access to home phone & $\mathrm{x}$ & $x$ & & & \\
\hline Population covered by a hazard mitigation plan & $\mathrm{x}$ & $x$ & & & \\
\hline Participation in the Community Rating System (CRS) & $x$ & $x$ & & & \\
\hline English proficiency & $x$ & $x$ & & $x$ & $x$ \\
\hline Mobile homes as percentage of total housing stock & $x$ & & & $x$ & $x$ \\
\hline Female workforce participation & $x$ & & & $x$ & \\
\hline
\end{tabular}

Most of the methods provide only comparative, not absolute results, and so some differences in the indices result from the range of communities or counties included in the analysis for each index. However, the relative results between communities are also inconsistent. For example, Mobile County hosts the city of Mobile and Hillsborough County contains Tampa, both the largest cities in their respective regions. Yet, depending on the index, these counties have either higher, lower, or equivalent resilience or vulnerability than the more suburban and rural counties that they neighbor. The different index rankings is troublesome for state and local policy, as it is unclear which areas are truly more at risk, or for what type of threat. More information is needed in order to identify which index should be used for what purpose, in order to clearly guide policy. 


\begin{tabular}{|c|c|c|c|c|c|c|}
\hline $\begin{array}{c}\text { Galveston } \\
\text { Region }\end{array}$ & $\begin{array}{l}\text { Cameron, LA } \\
\text { Jefferson, TX } \\
\text { Chambers, TX }\end{array}$ & & 뭉 & $\mathrm{N} / \mathrm{A}$ & & \\
\hline $\begin{array}{l}\text { Mobile } \\
\text { Region }\end{array}$ & $\begin{array}{l}\text { Mobile, AL } \\
\text { Baldwin, AL } \\
\text { Escambia, FL } \\
\text { Santa Rosa, FL }\end{array}$ & & N/A & E & $E$ & 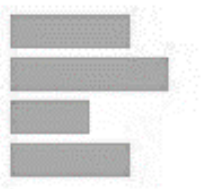 \\
\hline $\begin{array}{l}\text { Tampa } \\
\text { Region }\end{array}$ & $\begin{array}{l}\text { Hillsborough, } \mathrm{FL} \\
\text { Manatee, } \mathrm{FL} \\
\text { Sarasota, FL }\end{array}$ & & 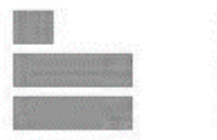 & & & 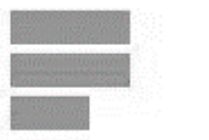 \\
\hline
\end{tabular}

Figure 6. Relative scores across indices for three sets of adjacent counties on the Gulf Coast. Vulnerability scores were inverted in Figure 6 for consistent comparison with the resilience indices. No data exists in the BRIC for the Galveston Region in the RCI for Baldwin County.

\section{VALIDATION METHODOLOGY}

This work undertakes a first effort at validating these indices in order to identify best practices for index development that is useful to guide policy and decision making. Our objective is to empirically validate each of the five disaster indices through multivariate regression analysis. We test the sign and significance of each index in explaining three disaster outcomes of interest, based on theory. We do not compare the magnitudes of each relationship, as these are determined, in part, by individual index assumptions and normalizations detailed above. This section details the methodology and data used for the analysis, as well as a justification for the regression form and selected variables.

\subsection{Outcome Variables}

Choice of outcomes to use for empirical validation must be grounded in theory. One logical choice is to use the stated objective of an index as a guide. For example, an index quantifying agricultural resilience to disasters may be empirically validated using crop or livestock losses. However, many disaster indices do not have specific objectives or focus on a critical system function, instead quantifying disaster resilience in general. Nonetheless, three outcomes are commonly mentioned in relation to index resilience and vulnerability: property damages, fatalities, 
and frequency of disaster declarations. ${ }^{(13,16)}$ These three outcomes are logically related to resilience and vulnerability, and also appealing due to readily accessible data. We acknowledge that resilience and vulnerability are characterized by much more than these three outcomes. Other important areas include reductions in psychological stress, minimizing electrical losses, or speedier economic recovery. We do not believe, nor intend for, our validation exercise to be comprehensive in testing for all types of outcomes. Instead, we present the results as an important first attempt at formal empirical validation and comparison across indices.

\subsection{Regression Analysis}

We employ multivariate regression analysis to empirically validate the explanatory power of the five disaster indices, relative to their theoretical performance, while controlling for other potential confounding variables.

For historical property losses, we construct a conditional damage function at the countyevent level, controlling for what is in harm's way as well as event characteristics. After specification testing, we select a log-log function for goodness of fit, but note that we do not take the natural log of the disaster indices, as three of the five indices' ranges include negative values. The resulting estimated coefficients on the disaster indices are semi-elasticities, interpreted as a unit change in the disaster index leading to a percent change in the outcome of interest. Note that one unit of each disaster index will be different, due to the differing formation and normalization algorithms used to create each index. We estimate our losses function using the Ordinary Least Squares (OLS) estimator:

$\ln \left(L_{i, j, t}\right)=\beta_{0}+\beta_{1} I_{i}+\beta_{2} \ln C_{i, t}+\beta_{3} \ln M_{i, t}+\beta_{4} \ln R_{i}+\mu_{i, j, t}$

where $L_{i, j, t}$ is the property loss in county $i$ due to disaster $j$ in year $t$, which is a function of the capital stock $\left(\mathrm{C}_{i, t}\right)$ of county $i$ in year $t$; the event magnitude $\left(\mathrm{M}_{i, t}\right)$ of disaster $j$ in year $t$; the underling disaster risk rate $\left(R_{i}\right)$; and the index level of resilience or vulnerability $\left(I_{i}\right)$ in county $i$. $\mu_{i, j, t}$ is the error term.

From our regression, we hypothesize that a well-performing resilience index would have a negative $\left(\beta_{1}<0\right)$ and statistically significant relationship with historical property losses, meaning 
that a higher resilience index value is correlated with lower levels of damage. A well-performing disaster vulnerability index would have a positive $\left(\beta_{1}>0\right)$ and statistically significant relationship with historical losses. This specification only includes observations with positive damages and does not sum up across all events to the county level as was the case in Peacock et al.. ${ }^{(13)}$ Staying at the county-event level, instead of the county level, gives us a larger sample and allows us to control for event-specific factors such as disaster magnitude.

In our sensitivity analysis, we also control for any disaster type-specific or year-specific confounding factors with fixed effects for disaster type, $\alpha_{j}$, and year, $\gamma_{t}$. We do not use county fixed effects as our disaster indices are time invariant and would be subsumed by the fixed effect. We also test the impact of different functional forms, including semi-log and linear, as well as population density and income instead of the capital stock. Lastly, we also test a count data estimator (negative binomial).

We next generate fatalities functions to empirically validate the indices. We use an almost identical regression framework to our damages function, except we substitute the population density (P) for the capital stock to control for people in harm's way. We use the Negative Binomial estimator, instead of OLS, as fatalities are a count variable ${ }^{3}$ :

$F_{i, j, t}=\beta_{0}+\beta_{1} I_{i}+\beta_{2} \ln P_{i, t}+\beta_{3} \ln R_{i}+\mu_{i, j, t}$

For sensitivity, we also test both including and omitting the disaster magnitude term for fatalities, as not all event observations have a recorded magnitude and the sample size will be much smaller, relative to the property losses regressions with large samples. We also estimate the fatality function with the use of fixed effects, but do not prefer it as our main result due to debate over proper implementation of fixed effects in a negative binomial model can call the results into question. ${ }^{(35)}$ Lastly, we test additional functional forms through the OLS estimator including log-log, semi-log, and linear.

Lastly, we model FEMA Disaster Declarations. The disaster declarations differ from the damage and fatality data in that the declaration outcome is a binary variable, but we only observe

\footnotetext{
${ }^{3}$ Damages are also a count variable. However, taking the natural log of damages transforms the data into a distribution approximating the normal distribution, making the Ordinary Least Squares estimator appropriate. At the same time, neither fatalities nor the natural log of fatalities follow a normal distribution, justifying the use of the Negative Binomial estimator due to over-dispersion in the data.
} 
cases where a disaster is declared. Thus, we transform the data into a count variable by summing the total number of disaster declarations by county during our sample time period. We analyze the frequency of disaster declarations by county in the following cross sectional approach:

$\log \left(D_{i}\right)=\beta_{0}+\beta_{1} I_{i}+\beta_{2} \ln P_{i}+\beta_{3} \ln R_{i}+\mu_{i}$

where the frequency of disaster declarations from 2000 to $2012\left(D_{i}\right)$ is a function of the disaster index value, average population from 2000 to 2012, and the underlying risk rate. For sensitivity, we also use population figures from 2000 and 2012, test the impact of income and capital stock instead of population, and also use a semi-log and linear specification. We do not use fixed effects, as time nor disaster-level variations are included in this model.

We note an important point regarding the $\beta_{1}$ coefficient across each of our regression equations. The interpretation of each $\beta_{1}$ coefficient is the percent change to the outcome of interest (damage, fatalities, or disaster declarations) resulting from a one unit increase in the respective disaster index. As such, the magnitude of $\beta_{1}$ depends greatly on the normalization assumption, which is unique to each index. Therefore, we do not consider the magnitude of the estimated $\beta_{1}$ coefficient in our validation tests nor do we compare the magnitudes of the $\beta_{1}$ coefficient across different disaster indices, as each disaster index is calculated using different geographic boundaries and normalization assumptions. A larger magnitude does not signify a superior index performance. Instead, we test the ability of each index in explaining outcomes consistent with the theoretical $\operatorname{sign}\left(\beta_{1}<0\right.$ for resilience indices and $\beta_{1}>0$ for vulnerability indices) and statistical significance of the relationship.

\subsection{Data Sources}

In order to estimate our empirical model, we assemble a panel dataset at the county-event level from 2000 to 2012 spanning ten Southeastern US states - Alabama, Florida, Georgia, Kentucky, Louisiana, Mississippi, North Carolina, South Carolina, Tennessee, and Texas. As shown in the index maps (Figures 1 through 5), BRIC, CDRI, and RCI only cover subsets of these ten states while SoVI and SVI cover the full extent. Also, some counties suffer more than one disaster in a year. A county with two disasters is included as two separate observations in our property loss and fatalities data sets. All together, the dataset includes more than 67,000 county- 
events representing more than $\$ 170$ billion in direct property losses (2009 \$USD), 3,394 lives lost, and 7,625 declared county-level disasters.

Property losses and direct fatalities at the county-event level are obtained from the National Climatic Data Center and adjust dollar values for inflation to 2009 \$USD (note that the base year for real dollars does not impact the model results). We collect disaster declarations at the countyevent level from the Federal Emergency Management Agency and the aggregate up to the county level to generate a count variable. Table II displays the summary statistics for our outcome variables. The large standard deviation of damages and fatalities indicates a long right tail for these distributions, a result of a few events with very high damages (e.g. Hurricane Katrina). Figures 7 , 8 , and 9 map the spatial distribution of damages, fatalities, and disaster declarations.

Table II: Outcome Variable Summary Statistics

\begin{tabular}{c|ccccc} 
Variable & $\begin{array}{c}\text { Number of } \\
\text { Observations }\end{array}$ & Mean & Standard Deviation & Minimum & Maximum \\
\hline Damages & 67,183 & $\$ 2,536,212$ & $\$ 108,000,000$ & $\$ 10.27$ & $\$ 19,500,000,000$ \\
Fatalities & 1,509 & 2.25 & 17.19 & 1 & 638 \\
Disaster Declarations & 1,054 & 7.24 & 3.46 & 1 & 19
\end{tabular}

Data for the five indices are publically available. BRIC, RCI, SoVI, and SVI all have websites with data readily accessible. Data on CDRI was found in the appendix of a doctoral thesis. ${ }^{(36)}$ We collated the indices based on the county FIPS code. We did not alter the index creators' normalization of any of the indices (see Section 3 for an explanation of the normalizations). However, two of the indices were not at the county level. For RCI (at the metropolitan level), we matched records with the FIPS code of the counties within the metropolitan area. For SVI (at the census track level), we averaged the final values across census blocks within each county. Table III presents summary statistics for the five disaster indices. 
Table III: Disaster Index Summary Statistics

\begin{tabular}{c|c|ccccc}
\multirow{2}{*}{ Variable } & Spatial Extent & $\begin{array}{c}\text { Number of } \\
\text { Observations }\end{array}$ & $\begin{array}{c}\text { Mean } \\
\text { Deviation }\end{array}$ & Minimum & Maximum \\
\hline CDRI & $\begin{array}{r}\text { Gulf Coast regions of TX, } \\
\text { LA, MS, AL, GA, FA }\end{array}$ & 143 & 0.00 & 0.43 & -1.32 & 1.44 \\
\hline \multirow{2}{*}{ BRIC } & $\begin{array}{c}\text { AL,FL, GA, KY, MS, NC, } \\
\text { SC, TN }\end{array}$ & 736 & 2.34 & 0.27 & 1.61 & 3.09 \\
\hline \multirow{2}{*}{ RCI } & $\begin{array}{c}\text { National } \\
\text { (Metro Regions Only) }\end{array}$ & 383 & -0.21 & 0.36 & -1.66 & 0.78 \\
\hline SoVI & National & 1,053 & 0.26 & 2.48 & -7.73 & 9.53 \\
\hline SVI & National & 1,053 & 7.60 & 1.05 & 3.17 & 11.08 \\
\hline
\end{tabular}

Lastly, we explain the control variables. The National Climatic Data Center reports disaster magnitudes for a subset of disaster events including flash flood, hail, high wind, strong wind, thunderstorm, and tornadoes. We perform a min-max normalization to the magnitudes, which subtracts the minimum magnitude or size across the observations of a given disaster type (e.g., tornado EF scale, hail size, etc.) and then divides by the maximum value, in order to compare intensities across different types of events. In the end, each disaster intensity has a value between 0 (least intense) and 1 (most intense). This normalization allows us to control for the intensity of each disaster event when the disaster records have different intensity units in the original data. We collect annual population density and real per capita income data from the U.S. Bureau of Economic Analysis. To estimate the capital stock, we follow a common method of using the scaled (multiplicative) interaction of population and per capita income. ${ }^{(37-39)}$ We scale this interaction by 2.87 - the average ratio of U.S. capita stock to Gross National Income during the second half of the twentieth century. However, the magnitude of this scale will only impact the constant term in the regression and not the estimate coefficient in our damages function. Finally, the underlying risk rate of disasters is generated by summing the total number of disaster events observed by county across our 12 year sample. 


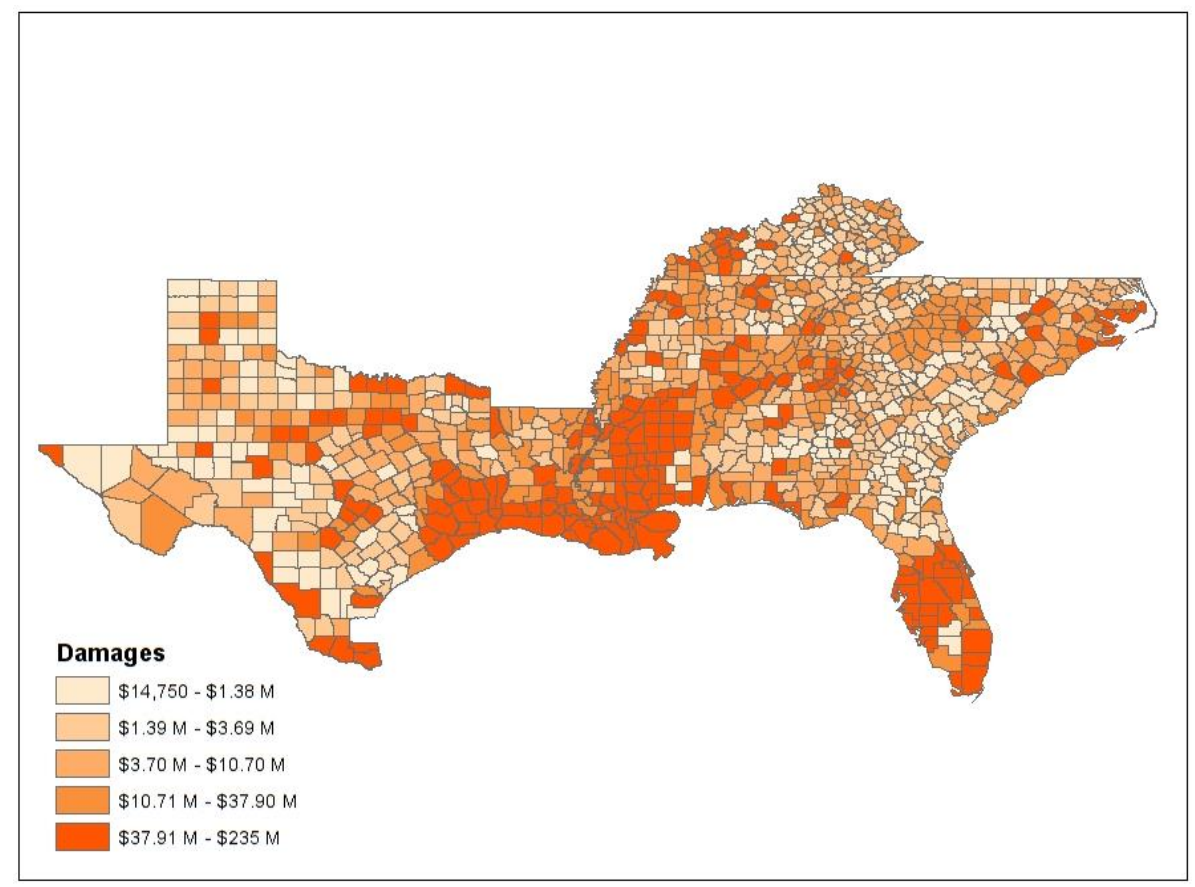

Figure 7: Total property losses by county (2009 \$USD, 2000-2012).

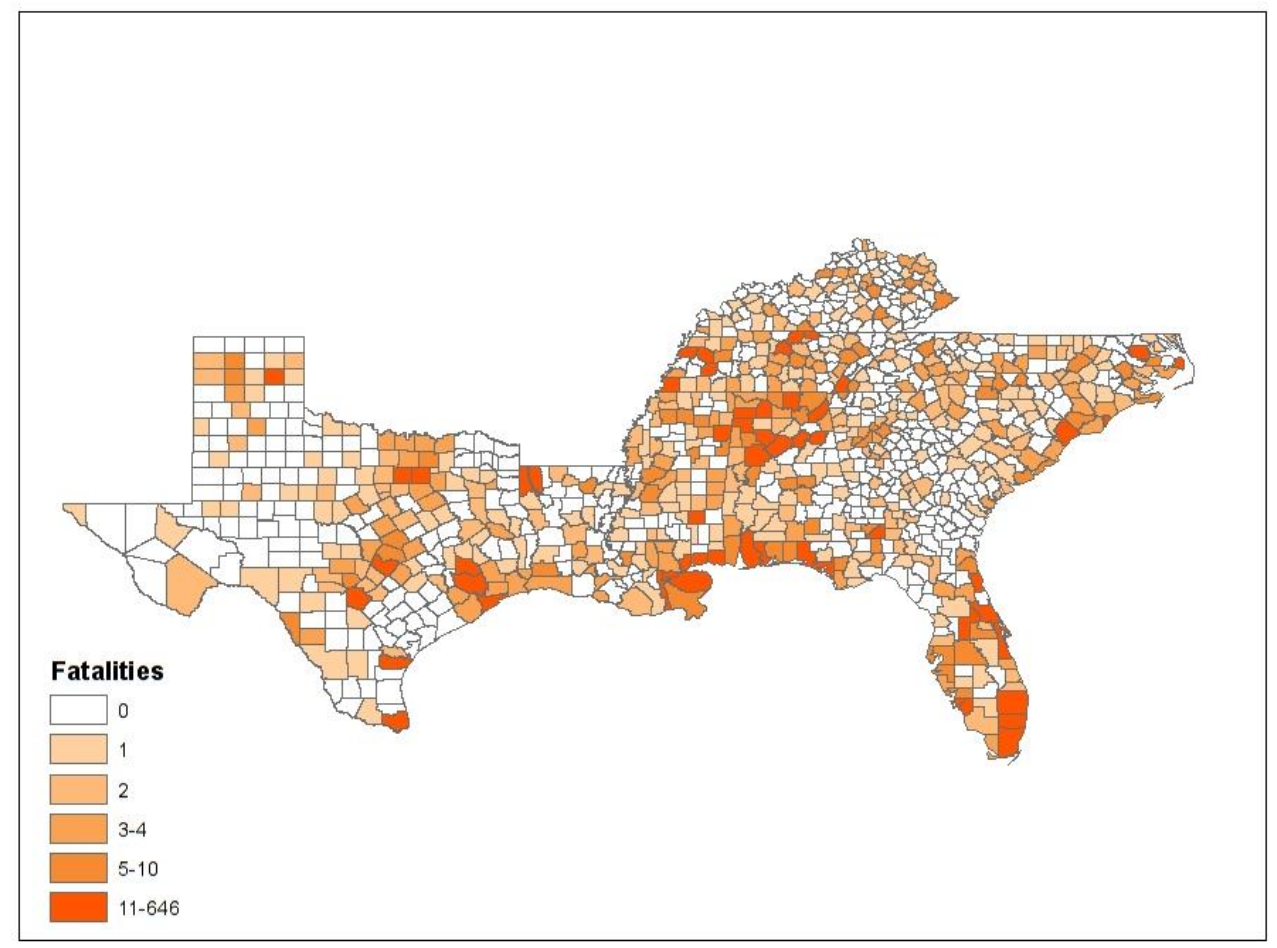

Figure 8: Total fatalities by county (2000-2012). 


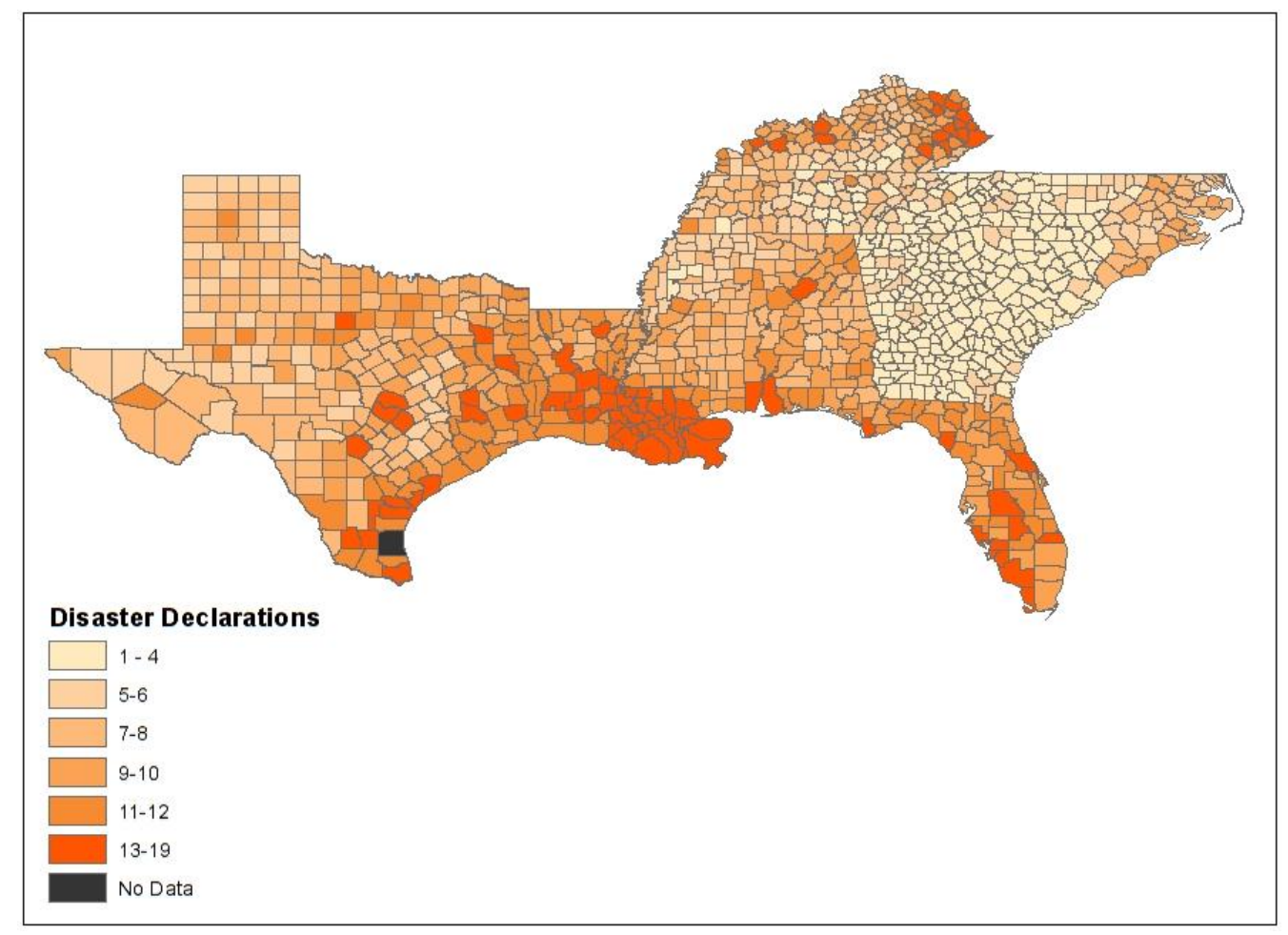

Figure 9: Total disaster declarations by county (2000-2012).

\section{RESULTS}

We compare the performance between indices in detail, and then present regression results for each index with the three outcome variables. Table IV gives pairwise correlations between the disaster indices across the counties that each pair of indices have in common. We present the pairwise correlation coefficients across the (geographically smaller) spatial intersection of all five indices in Appendix Table A1. The three resilience indices (BRIC, CDRI, RCI) are expected to be positively correlated, as are the two vulnerability indices (SOVI, SVI). Correlations across index type are expected to be negative and these cells are shaded gray in Table IV. While there is qualitative consistency within the index types, the overall correlations are not high. The highest correlations observed were between BRIC and CDRI at 0.805 . Half of the ten pairwise correlations have values of between -0.5 and 0.5 , with some values close to zero. Thus, it remains unclear, with only this information, whether disaster indices are picking up different facets of resilience and vulnerability or some indices are performing better. 
Table IV: Disaster Index Correlations.

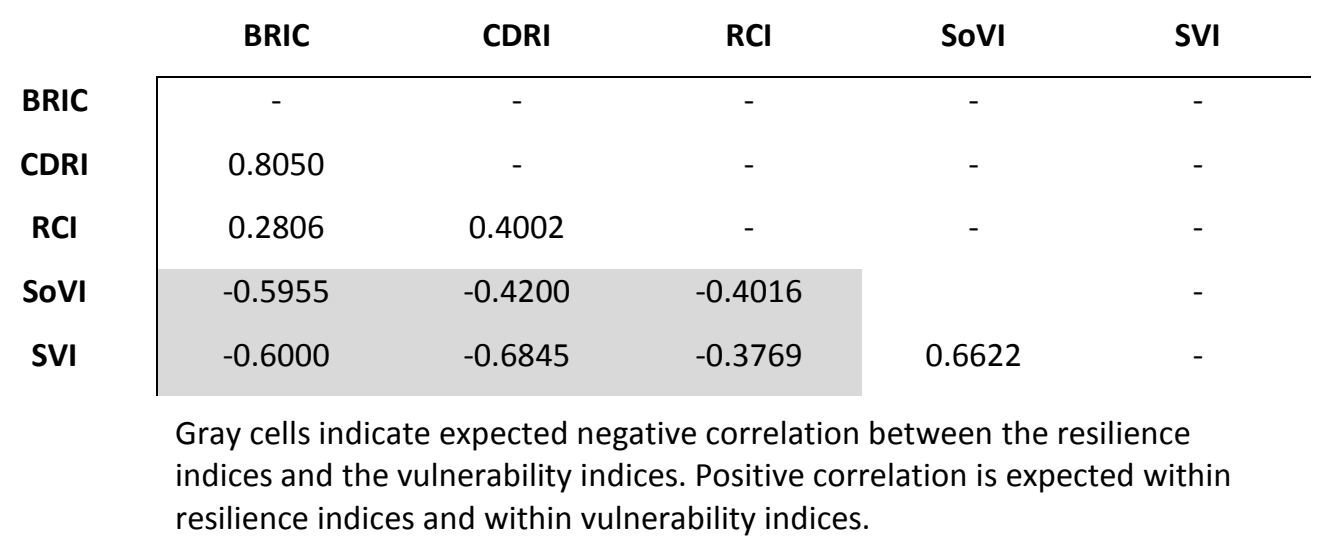

We also note that the correlation represent the noisiness and direction of relationship between two variables, but does not reflect the slope of the linear relationship. In addition, it does not capture non-linear relationships or the relationship between the variables and a third variable. Lastly, given that these indices are generated across varying geographic extents, these results only represent the correlation between two indices across the spatial extents that they share. Therefore, we place most confidence in our regression results to examine the relationship between each index and the three outcomes of interest, controlling for other confounding factors. As such, indices that are highly correlated may not perform similarly in the regression analysis.

Table VIII summarizes the regression results of each index with each outcome variable. Filled circles indicate the index performed as expected (and with statistical significance): negative correlation between disaster impacts and resilience and positive correlation between disaster impacts and vulnerability. Open circles indicate that index performance was opposite from expected (and with statistical significance) and no circles indicate that the results were not significantly different from zero. Overall, CDRI and SoVI perform the best, with all results of the correct sign, but the estimated coefficient on disaster declarations and fatalities, respectively, are not statistically significant. This may be partly driven by the fact that they were already empirically verified to some extent in the original analysis. In addition, RCI performs as expected for property losses and fatalities, but has an insignificant but incorrect sign for declarations. CDRI, RCI, and SVI perform best for both damages and fatalities, while SoVI performs best for both damages and disaster declarations. The results of each analysis are discussed in further detail below. 
Table VIII: Summary of index validation results for property damages, fatalities, and disaster declarations.

\begin{tabular}{|c|c|c|c|}
\hline Index & $\begin{array}{l}\text { Property } \\
\text { Damages }\end{array}$ & Fatalities & $\begin{array}{c}\text { Disaster } \\
\text { Declarations }\end{array}$ \\
\hline BRIC & O & & 0 \\
\hline CDRI & $\bullet$ & $\bullet$ & \\
\hline RCI & $\bullet$ & $\bullet$ & \\
\hline SoVI & $\bullet$ & & $\bullet$ \\
\hline SVI & $\bullet$ & $\bullet$ & 0 \\
\hline \multicolumn{4}{|c|}{$\begin{array}{l}\text { - Filled circles indicate correlation is of the expected sign and statistically significant. } \\
\text { o Open circles indicate correlation is of the opposite sign and statistically significant. } \\
\text { No circle indicates regression results were not statistically different than zero. }\end{array}$} \\
\hline
\end{tabular}

\subsection{Empirical Validation Results}

\subsubsection{Property Losses}

Table $\mathrm{V}$ presents the results of the damage functions, which analyze index performance in explaining historical property losses. Columns 1 through 5 show the logs of damages by index. The analysis controls for the county-level capital stock, normalized disaster magnitude, and the underlying risk rate. Robust standard errors are shown in the parentheses. We consider an index to perform well if the estimated coefficient is of the hypothesized sign (negative for resilience and positive for vulnerability indices) and with statistical significance. Given the disparate spatial scales and normalizations, we do not compare the magnitudes of the estimated index coefficients. The estimated index coefficients can be interpreted as the percent change in damages, given a one (normalized) unit increase in the disaster index. All indices but BRIC perform well in explaining damages. These results are consistent with Peacock et al.'s (2010) analysis of CDRI, despite our different regression approaches. The positive correlation of the BRIC resilience index with damages was unexpected, as this index contains many carefully chosen variables and is highly cited. The BRIC specification was tested for multicollinearity, but the Variance Inflation Factor for each variable was under 3.5, despite a high correlation between BRIC and the capital stock (removing the capital stock, however, did not change the sign or significance). 
We perform multiple specifications to analyze the sensitivity of each index including the use of fixed effects, log-linear and linear specification, negative binomial estimator, and different control variables. CDRI remained consistent across all specifications. RCI, SoVI, and SVI have opposite signs, but not with significance, in only a few specifications. BRIC had the correct (negative) sign in the negative binomial specification, but lacked statistical significance. Otherwise, the results held in direction and significance across all specifications.

Table V: Damage Functions with Disaster Indices

\begin{tabular}{|c|c|c|c|c|c|}
\hline VARIABLES & $\begin{array}{c}(1) \\
\text { Ln Damages }\end{array}$ & $\begin{array}{c}\text { (2) } \\
\text { Ln Damages }\end{array}$ & $\begin{array}{c}(3) \\
\text { Ln Damages }\end{array}$ & $\begin{array}{c}\text { (4) } \\
\text { Ln Damages }\end{array}$ & $\begin{array}{c}(5) \\
\text { Ln Damages }\end{array}$ \\
\hline BRIC & $\begin{array}{c}0.311 * * * \\
(0.0569)\end{array}$ & & & & \\
\hline CDRI & & $\begin{array}{c}-0.366^{* * *} \\
(0.0665)\end{array}$ & & & \\
\hline $\mathrm{RCl}$ & & & $\begin{array}{c}-0.159 * * * \\
(0.0387)\end{array}$ & & \\
\hline SoVI & & & & $\begin{array}{c}0.0633^{* * *} \\
(0.00473)\end{array}$ & \\
\hline SVI & & & & & $\begin{array}{c}0.0893 * * * \\
(0.0100)\end{array}$ \\
\hline Ln Risk Rate & $\begin{array}{c}-0.148^{* * *} \\
(0.0161)\end{array}$ & $\begin{array}{c}-0.251^{* * *} \\
(0.0490)\end{array}$ & $\begin{array}{c}-0.312^{* * *} \\
(0.0231)\end{array}$ & $\begin{array}{c}-0.246 * * * \\
(0.0148)\end{array}$ & $\begin{array}{c}-0.265^{* * *} \\
(0.0148)\end{array}$ \\
\hline Ln Magnitude & $\begin{array}{l}1.509 * * * \\
(0.0445)\end{array}$ & $\begin{array}{c}0.428 * * * \\
(0.0688)\end{array}$ & $\begin{array}{l}1.061 * * * \\
(0.0522)\end{array}$ & $\begin{array}{l}1.266^{* * *} \\
(0.0364)\end{array}$ & $\begin{array}{l}1.268^{* * *} \\
(0.0366)\end{array}$ \\
\hline Ln Capital Stock & $\begin{array}{c}0.0183 \\
(0.0135)\end{array}$ & $\begin{array}{c}0.248^{* * *} \\
(0.0221)\end{array}$ & $\begin{array}{c}0.230 * * * \\
(0.0118)\end{array}$ & $\begin{array}{l}0.176^{* * *} \\
(0.00859)\end{array}$ & $\begin{array}{l}0.152 * * * \\
(0.00832)\end{array}$ \\
\hline Constant & $\begin{array}{c}9.407^{* * *} \\
(0.191)\end{array}$ & $\begin{array}{c}4.580 * * * \\
(0.364)\end{array}$ & $\begin{array}{c}5.809 * * * \\
(0.226)\end{array}$ & $\begin{array}{c}7.067^{* * *} \\
(0.168)\end{array}$ & $\begin{array}{c}6.986 * * * \\
(0.202)\end{array}$ \\
\hline Observations & 32,899 & 4,600 & 18,462 & 41,916 & 41,916 \\
\hline R-squared & 0.102 & 0.040 & 0.066 & 0.085 & 0.083 \\
\hline
\end{tabular}

Robust standard errors in parentheses

${ }^{* * *} p<0.01,{ }^{* *} p<0.05, * p<0.1$

\subsubsection{Fatalities}

Table VI displays the results of the fatalities functions. The functional form is identical to that of damages, except for our dependent variable (direct deaths), the inclusion of (the natural log of) population density in lieu of the capital stock to control for what is in harm's way, the exclusion of the disaster magnitude, and the estimator (negative binomial instead of ordinary least squares, 
due to the count nature of the data). Again, we compare each estimated index coefficient to the theoretical sign and do not compare the magnitudes across indices, as they are a function of individual index normalizations and other assumptions. While all of the five disaster indices had the proper sign, only three of the five (CDRI, RCI, and SVI) are statistically different from zero. The CDRI also performed well in explaining the magnitude of fatalities in flood deaths as part of Peacock et al.'s ${ }^{(13)}$ empirical validation of the index. Although Peacock et al. do note that CDRI incorrectly explained the probability of some fatality occurring, a majority of the flood fatalities in their sample were driven by Hurricane Katrina, whereas the fatalities in this data are from a wider range of events. In our sensitivity analysis, CDRI and RCI remain consistent and as expected across all specifications. SoVI also performs well. SVI has opposite signs when using fixed effects and BRIC was sensitive to the functional form. Other robustness checks including the inclusion of event magnitude, ordinary least squares, and fixed effects were run but did not change the qualitative results.

Table VI: Fatalities Functions with Disaster Indices

\begin{tabular}{|c|c|c|c|c|c|}
\hline VARIABLES & $\begin{array}{c}(1) \\
\text { Fatalities }\end{array}$ & $\begin{array}{c}(2) \\
\text { Fatalities }\end{array}$ & $\begin{array}{c}(3) \\
\text { Fatalities }\end{array}$ & $\begin{array}{c}\text { (4) } \\
\text { Fatalities }\end{array}$ & $\begin{array}{c}(5) \\
\text { Fatalities }\end{array}$ \\
\hline BRIC & $\begin{array}{l}-0.154 \\
(0.247)\end{array}$ & & & & \\
\hline CDRI & & $\begin{array}{c}-1.009 * * \\
(0.419)\end{array}$ & & & \\
\hline $\mathrm{RCl}$ & & & $\begin{array}{c}-0.638^{* *} \\
(0.256)\end{array}$ & & \\
\hline SoVI & & & & $\begin{array}{c}0.135 \\
(0.0906)\end{array}$ & \\
\hline SVI & & & & & $\begin{array}{c}0.125^{*} \\
(0.0705)\end{array}$ \\
\hline Ln Risk Rate & $\begin{array}{c}-0.0983^{* * *} \\
(0.0306)\end{array}$ & $\begin{array}{c}-0.563^{* * *} \\
(0.201)\end{array}$ & $\begin{array}{l}-0.361 * \\
(0.212)\end{array}$ & $\begin{array}{c}-0.243^{* *} \\
(0.106)\end{array}$ & $\begin{array}{l}-0.229 * \\
(0.123)\end{array}$ \\
\hline Ln Avg. Population Density & $\begin{array}{c}0.000190 \\
(0.0402)\end{array}$ & $\begin{array}{c}0.501^{* *} \\
(0.230)\end{array}$ & $\begin{array}{c}0.297 \\
(0.267)\end{array}$ & $\begin{array}{l}0.276^{*} \\
(0.157)\end{array}$ & $\begin{array}{c}0.266 \\
(0.182)\end{array}$ \\
\hline Constant & $\begin{array}{c}1.120^{* *} \\
(0.499)\end{array}$ & $\begin{array}{l}-0.170 \\
(0.952)\end{array}$ & $\begin{array}{l}-0.267 \\
(1.106)\end{array}$ & $\begin{array}{l}-0.216 \\
(0.567)\end{array}$ & $\begin{array}{l}-1.154 \\
(1.151)\end{array}$ \\
\hline Observations & 1,064 & 384 & 985 & 1,509 & 1,509 \\
\hline
\end{tabular}

Robust standard errors in parentheses

*** $p<0.01,{ }^{* *} p<0.05, * p<0.1$ 


\subsubsection{Disaster Declarations}

Results of the disaster declaration functions are presented in Table VII. Unlike for damages and fatalities, this approach is purely cross-sectional (no fixed effects or variation over time), with the count of disaster declarations per county from 2000 to 2012 as the dependent variable. As such, an event magnitude is not included, but the disaster risk rate as well as the underlying population ${ }^{4}$ are controlled for. The SoVI performs best, as it is positively related to disaster declarations and is statistically significant. This is a better performance than was found in the correlation analysis performed by Cutter et al.. ${ }^{(16)}$ The CDRI also has the expected (negative) coefficient, but it not statistically significant. The three remaining indices (BRIC, RCI, and SVI) all perform the opposite as expected and with statistical significance. Many factors explain disaster declarations, including political factors $^{(16)}$, so this is perhaps the least reliable outcome of the three we test. However, it is a striking finding, nonetheless. In sensitivity analysis, BRIC remained positive and statistically significant across all specifications, counter to the theoretical negative result, while SoVI performed strongly throughout. CDRI, RCI, and SVI remained indistinguishable from zero in most specifications.

\footnotetext{
${ }^{4} \mathrm{We}$ also control for the underlying capital stock and find qualitatively similar results, but find that population performs better.
} 
Table VII: Disaster Declaration Functions with Disaster Indices

\begin{tabular}{|c|c|c|c|c|c|}
\hline VARIABLES & $\begin{array}{c}\text { (1) } \\
\text { Ln Disaster } \\
\text { Declarations }\end{array}$ & $\begin{array}{c}\text { (2) } \\
\text { Ln Disaster } \\
\text { Declarations }\end{array}$ & $\begin{array}{c}\text { (3) } \\
\text { Ln Disaster } \\
\text { Declarations }\end{array}$ & $\begin{array}{c}\text { (4) } \\
\text { Ln Disaster } \\
\text { Declarations } \\
\end{array}$ & $\begin{array}{c}\text { (5) } \\
\text { Ln Disaster } \\
\text { Declarations }\end{array}$ \\
\hline BRIC & $\begin{array}{c}1.034 * * * \\
(0.114)\end{array}$ & & & & \\
\hline CDRI & & $\begin{array}{c}-0.0530 \\
(0.0602)\end{array}$ & & & \\
\hline $\mathrm{RCl}$ & & & $\begin{array}{l}0.0341 \\
(0.105)\end{array}$ & & \\
\hline SoVI & & & & $\begin{array}{c}0.0299 * * * \\
(0.00910)\end{array}$ & \\
\hline SVI & & & & & $\begin{array}{c}-0.0289^{*} \\
(0.0174)\end{array}$ \\
\hline Ln Risk Rate & $\begin{array}{c}0.0916 * * * \\
(0.0272)\end{array}$ & $\begin{array}{r}-0.00801 \\
(0.0292)\end{array}$ & $\begin{array}{c}0.0786^{* *} \\
(0.0393)\end{array}$ & $\begin{array}{c}0.0974 * * * \\
(0.0239)\end{array}$ & $\begin{array}{c}0.0921^{* * *} \\
(0.0238)\end{array}$ \\
\hline Ln Avg. Population Density & $\begin{array}{c}-0.271^{* * *} \\
(0.0308)\end{array}$ & $\begin{array}{c}0.0484 * * \\
(0.0203)\end{array}$ & $\begin{array}{c}-0.0510^{*} \\
(0.0265)\end{array}$ & $\begin{array}{l}-0.0310^{*} \\
(0.0162)\end{array}$ & $\begin{array}{c}-0.0701^{* * *} \\
(0.0138)\end{array}$ \\
\hline Constant & $\begin{array}{l}0.0721 \\
(0.227)\end{array}$ & $\begin{array}{c}2.238^{* * *} \\
(0.101)\end{array}$ & $\begin{array}{c}1.777^{* * *} \\
(0.171)\end{array}$ & $\begin{array}{c}1.578^{* * *} \\
(0.0903)\end{array}$ & $\begin{array}{c}1.981^{* * *} \\
(0.159)\end{array}$ \\
\hline Observations & 736 & 143 & 382 & 1,053 & 1,053 \\
\hline R-squared & 0.113 & 0.036 & 0.011 & 0.030 & 0.022 \\
\hline
\end{tabular}

Robust standard errors in parentheses

*** $\mathrm{p}<0.01, * * \mathrm{p}<0.05, * \mathrm{p}<0.1$

\section{DISCUSSION}

The five indices analyzed here were all theoretically sound and individual metrics were analyzed using statistical techniques during index creation. However, empirical validation reveals that not all indices perform as expected. While most indices explain historical damages consistent with our hypotheses, only some explain fatalities and few explain disaster declarations with significance. We acknowledge that this is an initial and incomplete attempt at validation. Most of the indices' authors do not specifically state that their indices will explain the three outcomes tested here. We further understand that resilience goes beyond simply withstanding disruptive events and speaks to the ability of a system to recover from disturbances and adapt to changing conditions. However, these results highlight the important need for individual indices to carefully describe their intended purposes. It would indeed be unfair to expect an index to explain a specific outcome when it was not intended to predict it. However, very few indices specifically explain the outcomes that they try to speak to, so the reader is left to decide for him or herself. We review key types of 
purposes, as well as index limitations, in this section. Unfortunately, end users often apply indices to a host a different questions and problems, even ones for which the indices may have not been intended. One recommendation of this paper is that indices should be much clearer in what they aim to explain and should follow up with explicit testing to see if they indices perform well. This way, decision makers can know clearly which index to choose to inform certain types of decisions.

Recent policies calling for disaster preparedness and investment drives local, state, and federal managers to look for information explaining levels of resilience and vulnerability in their jurisdictions. These index approaches have been designed to be readily accessible and replicable. Our main finding is that — despite connections between input metrics and aggregation methodsindex performance varies greatly across the five disaster indices analyzed here. It is difficult to validate measures of performance for infrequent events where specific community and disaster conditions are never exactly the same. Instead, we have developed recommendations to support improvement or development of resilience indices that allow for partial validation (across specific outcomes) and can more directly inform policy and investment decisions.

\subsection{Critical Functions}

While an index of overall system performance has utility for comparative purposes, communities are complex systems that perform many functions for which aggregation may obscure relevant results. Furthermore, unlike cyber-networks, military installations, or energy grids, communities rarely have a single managing authority that can make decisions for the entire system. We recommend identifying the critical functions of a community, such as electricity, telecommunications, transportation, housing/shelter, or specific industries whose continued operation will be crucial for maintaining a flow of funds during recovery. Grouping index metrics according to critical function will allow the generation of sub-scores that are useful to different decision makers with specific authority, responsibility, or capacity in each of these functional areas. The specific identification of critical functions also permits outcomes of these functions to be specifically chosen for validation.

\subsection{Stages of Disruption}

Following grouping by critical function, indices can also be enhanced through categorization of metrics according to the stages of a disruptive event. This process improves index 
utility in two ways. First, it ensures that the index contains metrics that are indicative of performance at all stages of a disruption, not just the initial event, and that no stage is overlooked or underrepresented. Metrics of the CDRI were internally classified as related to mitigation, preparedness, response, and recovery and it is the highest performing index of our sample. Secondly, grouping according to stage further improves the ability to perform partial validation on subsets of the data. The analysis described here uses outcomes largely related to the initial disasters event. However, if metrics within the indices were clearly described as being important for one or more of stages - absorbing the initial shock, recovering and reducing secondary impacts, or longterm adaptation and mitigation - each group of metrics could be independently validated against more specific outcomes. For example, number or school closing days, or change in population could be used as outcomes to indicate performance in the recovery or adaptation stages. Linkov et al. have developed a guiding framework that can be used to organize existing metrics and indices to support these validation goals. $(40,48,49,50)$

\subsection{Sensitivity to Scale}

Lastly, the use of relative index methods requires closer attention to scale. The indices presented here have been normalized or reported with qualitative scores that are only relative to the maximum and minimum score within the region of analysis. Consequently, the resulting magnitudes of the empirical validation results are not directly comparable across indices. We instead compare each result only to how it should perform based on theory. Not much discussion has been given to the variability of individual method results when applied at different scales. In order to aid stakeholders and decision makers in interpreting the results, it is important to perform some sensitivity analysis on newly created indices and clearly communicate the implications for interpretation of the results. It is also crucial to clearly discuss if the metrics selected are intended to be widely applicable, or mostly relevant only to the region, scale, and/or subset of disasters considered in the published demonstration.

\section{CONCLUSION}

Empirical validation remains a fundamental, but rarely attempted, final step for disaster index creation. ${ }^{(1)}$ We find that the CDRI, RCI, and SVI indices perform best for explaining 
damages and fatalities, while SoVI performs best for damages and disaster declarations. However, we encourage end users to carefully think about the strengths and weaknesses of each index before making a decision about which to implement. We stress that these results are not meant to condemn an index for poor performance as there are numerous potential outcomes that a disaster index may address. We do believe, however, that the outcomes we use are logically based and well justified for the purposes of this paper. In order to understand which index should be used for different purposes, it is fundamentally important to have a clear purpose and to empirically validate the final index based on that purpose. However, even if an index has a clear purpose and is empirically verified, there are still limitations to the policy relevance as it may not be clear which metrics can be improved to increase resilience. Unfortunately, aggregate level validation does not address this. Further, if the indices are all relative, improvements in resilience across all locations will not be reflected in the index. While great strides have been made thus far in the arena, important work remains to quantify resilience and vulnerability. Index approaches may have most utility as a screening level tool that can be used to identify specific critical function for further investigation and modeling, such as through a network science approach ${ }^{(47)}$, than as a decision support tool for direct community investment.

Understanding community resilience and vulnerability to natural disasters remains a policy priority around the world. Corporations, governments, and non-profit organizations are investing time and resources into measuring and improving resilience across many disciplines, so much so that the term has evolved into a new identity. ${ }^{(28,41-43)}$ Quantifying resilience and vulnerability through aggregation of theoretically justified metrics has become a popular approach to aid in decision making. However, we show that empirical validation remains an important final step. While indices may be well substantiated by theory, they may not perform as expected. We show that this is often the case with five top disaster indices in the United States by validating index performance against property losses, damages, and fatalities. Although some indices may not have been intended to assess the outcomes we selected, a lack of clear index purpose or definition of relevant outcomes decreases the policy relevance. Clearer, validated index functionality is fundamentally important in order to better understand the value of index results and properly apply these lessons for their intended purposes. By validating index performance using outcomes related to the stated objectives of the indices, policy makers can have confidence that improvements in 
resilience or reduction in vulnerability, as recorded by changes in a disaster index, will translate to specific desired improvements.

\section{ACKNOWLEDGEMENTS}

The authors would like to thank Dr. Susan Cutter for her very thoughtful and helpful comments on an earlier draft of the paper. Permission was granted by authority of the USACE Chief of Engineers to publish this material. The views and opinions expressed in this paper are those of the individual authors and not those of the U.S. Army, or other sponsor organizations.

\section{REFERENCES}

1. Kahn M. The death toll from natural disasters: The role of income, geography, and institutions. The Review of Economics and Statistics. 2005; 87:271-284.

2. Mallin M, Corbett, C. How hurricane attributes determine the extent of environmental effects: multiple hurricanes and different coastal systems. Estuaries and Coasts. 2006; 29(6):1046-1061.

3. Norris F, Friedman M, Watson P, Byrne C, Diaz E, Kaniasty K. 60,000 disaster victims speak: part I. An empirical review of the empirical literature, 1981-2001. Psychiatry. 2000; 65(3), 207-239.

4. Pelling M, Özerdem A, Barakat S. The macro-economic impact of disasters. Progress in Development Studies. 2002; 2(4), 283-305.

5. Cavallo E, Noy I. Natural disasters and the economy-a survey. International Review of Environmental and Resource Economics. 2011;5(1), 63-102.

6. Field C. Managing the risks of extreme events and disasters to advance climate change adaptation: special report of the intergovernmental panel on climate change. Cambridge University Press; 2012. 
7. Executive Order No. 13653. Preparing the United States for the Impacts of Climate Change. Federal Register. 2013;78(215):66819-66824.

8. Executive Order No. 13677. Climate-Resilient International Development. Federal Register. 2014;79(187):58231-58236.

9. US Department of Housing and Urban Development. HUD Launches \$1 Billion National Disaster Resilience Competition. Press Release. [Internet]. [2014; cited 2015] Available from:http://portal.hud.gov/hudportal/HUD?src=/press/press_releases_media_advisories/2 014/HUDNo_14-109.

10. Lum T, and Margesson R. Typhoon Haiyan (Yolanda): U.S. and International Response to Philippines Disaster. 2014. Congressional Research Service Report R43309.

11. United Nations. Disaster Resilience Measurements: Stocktaking of Ongoing Efforts in Developing Systems for Measuring Resilience. Technical Report. 2014.

12. Cutter S, Burton C, Emrich C. Disaster resilience indicators for benchmarking baseline conditions. Journal of Homeland Security and Emergency Management. 2010; 7(1).

13. Peacock W, Brody S, Seitz W, Merrell W, Vedlitz A, Zahran S, Harriss R, Stickney R. Advancing Resilience of Coastal Localities: Developing, Implementing, and Sustaining the Use of Coastal Resilience Indicators: A Final Report. Hazard Reduction and Recovery Center. 2010.

14. Foster K. Building Regional Resilience: Urban and Regional Policy and Its Effects, Vol 2. Brookings Institute Press; 2012. Ch. 2: In search of regional resilience. P. 24-59.

15. Berkley Building Resilient Regions. Resilience Capacity Index. [Internet]. [2015; cited 2015]. Available from: brr.berkeley.edu/rci/. 
16. Cutter S, Boruff B, Shirley W. Social Vulnerability to Environmental Hazards. Social Science Quarterly. 2003; 84(2):242-261.

17. Flanagan B, Gregory E, Hallisey E, Heitgerd J, Lewis B. A social vulnerability index for disaster management. Journal of Homeland Security and Emergency Management, 2011; $8(1)$.

18. Holling C. Resilience and stability of ecological systems. Annual review of ecology and systematics, 1973; 1-23.

19. Martin-Breen P, Anderies J. Resilience: a literature review. The Rockefeller Foundation. [Internet.] [2011; cited 2015]. Available from https://ids.ac.uk.

20. Fletcher D, Sarkar M. Psychological resilience a review and critique of definitions, concepts, and theory. European Psychologist, 2013; 18(1):12-23.

21. Pielke R, Landsea C, Mayfield M, Laver J, Pasch R. Hurricanes and global warming. Bulletin of the American Meteorological Society, 2005; 86(11).

22. United Nations. Natural hazards, unnatural disasters: the economics of effective prevention. The World Bank; 2010.

23. Birkmann E. Measuring Vulnerability to Natural Hazards: Toward Disaster Resilient Societies. New York: United Nations University Press; 2006.

24. National Academy of Sciences. Disaster resilience: a national imperative. Technical Report. Washington DC, United States. [Internet] [2012; cited 2015] Available from: http://www.nap.edu/catalog.php?record_id=13457

25. Field C, Barros V, Stocker T, Qin D, Dokken D, Ebi K, Mastrandrea M, Mach K, Plattner G, Allen S, Tignor M, Midgley P, Eds. Managing the Risks of Extreme Events and Disasters to Advance Climate Change Adaptation. A Special Report of Working Groups I 
and II of the Intergovernmental Panel on Climate Change. Cambridge and New York: Cambridge University Press; 2012.

26. Gitay H, Bettencourt S, Kull D, Reid R, McCall K, Simpson A, Krausing J, Ebinger J, Ghesquiere F, Fay M. Main report. Vol. 1 of Building resilience: integrating climate and disaster risk into development - the World Bank Group experience. Washington DC:World Bank; 2013.

27. Adger W. Vulnerability. Global environmental change. 2006; 16(3), 268-281.

28. Linkov I, Bridges T, Creutzig F, Decker J, Fox-Lent C, Kröger W, Thiel-Clemen. Changing the resilience paradigm. Nature Climate Change. 2014; 4(6), 407-409.

29. Gallopín G. Linkages between vulnerability, resilience, and adaptive capacity. Global environmental change, 2006; 16(3), 293-303.

30. Hazards and Vulnerability Research Institute. Social Vulnerability Index for the United States. [Internet. $] \quad[2010, \quad$ cited 2015] Available at: http://webra.cas.sc.edu/hvri/products/sovi.aspx.

31. Burton C. A Validation of Metrics for Community Resilience to Natural Hazards and Disasters Using the Recovery from Hurricane Katrina as a Case Study. Annals of the Association of American Geographers. 2015; 105(1), 67-86.

32. Cutter S, Ash K, Emrich C. The geographies of community disaster resilience. Global Environmental Change. 2014; 29, 65-77.

33. Hazards and Vulnerability Research Institute. DRRC: Baseline Indicators for Monitoring Disaster Resilience in Rural Places. [Internet.] [2015; cited 2015]. Available from: http://webra.cas.sc.edu/hvri/research/drrc_resilience.aspx. 
34. Cutter S. Vulnerability to Environmental Hazards. Progress in Human Geography 1996; 20(4):529-39.

35. Allison P, Waterman R. Fixed-effects negative binomial regression models. Sociological methodology. 2002; 32(1), 247-265.

36. Mayunga J. Measuring the measure: A multi-dimensional scale model to measure community disaster resilience in the US Gulf Coast region, Doctoral dissertation: Texas A\&M University. 2009.

37. Bakkensen L, Mendelsohn R. Risk and Adaptation: Evidence from Global Hurricane Damages and Fatalities. Forthcoming. Journal of the Association of Environmental and Resource Economics.

38. Hallegatte S, Green C, Nicholls R, Corfee-Morlot J. Future flood losses in major coastal cities. Nature climate change, 2013; 3(9), 802-806.

39. Kamps, C. New estimates of government net capital stocks for 22 OECD countries 19602001. Technical Report. International Monetary Fund. 2004;4-67.

40. Linkov I, Eisenberg D, Bates M, Chang D, Convertino M, Allen J, Flynn S, Seager T. Measurable resilience for actionable policy. Environ Sci Technol 2013; 47:10108-10110.

41. Larkin S, Fox-Lent C, Eisenberg D, Trump B, Wallace S, Chadderton C, Linkov I. Benchmarking agency and organizational practices in resilience decision making. Environment Systems and Decisions, 2015: 35(2), 185-195.

42. United Nations Office for Disaster Risk Reduction The R!SE Initiative: Disaster Risk Sensitive Investments, Program Summary. Version 2. [Internet.] [2014; cited 2015]. Available from: www.theriseinitiative.org. 
43. ARUP. City Resilience Index: City Resilience Framework. The Rockefeller Foundation. [Internet]. $\quad$ [2014; cited 2015]. Available at: https://www.rockefellerfoundation.org/report/city-resilience-framework/

44. GOV.UK. Preparation and planning for emergencies: the National Resilience Capabilities Programme. UK National Resilience Capabilities Programme. [Internet]. [2014; cited 2016]. Available at: https://www.gov.uk/guidance/preparation-and-planning-foremergencies-the-capabilities-programme

45. Government of Canada. Canada's National Disaster Mitigation Strategy [Internet]. [2008; cited 2016]. Available at: http://www.publicsafety.gc.ca/cnt/mrgnc-mngmnt/dsstr-prvntn$\underline{\text { mtgtn/ntnl-dsstr-mtgtn-strtg-eng.aspx }}$

46. Ministerio De Economia, Republica Dominicana. Programa de Prevencion de Desastres Y Geston de Riesgos (1708/OC-DR). [Internet]. [2013; cited 2016]. http://dgodt.gob.do/index.php/programasyproyectos/gestion-de-riesgos

47. Ganin, A. A., Massaro, E., Gutfraind, A., Steen, N., Keisler, J. M., Kott, A., ... \& Linkov, I. (2015). Operational resilience: concepts, design and analysis. Sci. Rep. 6, 19540; doi: 10.1038/srep19540 (2016).

48. Fox-Lent, C., Bates, M. E., \& Linkov, I. (2015). A matrix approach to community resilience assessment: an illustrative case at Rockaway Peninsula. Environment Systems and Decisions, 35(2), 209-218.

49. Linkov, I., Eisenberg, D. A., Plourde, K., Seager, T. P., Allen, J., \& Kott, A. (2013). Resilience metrics for cyber systems. Environment Systems and Decisions, 33(4), 471476.

50. Roege, P. E., Collier, Z. A., Mancillas, J., McDonagh, J. A., \& Linkov, I. (2014). Metrics for energy resilience. Energy Policy, 72, 249-256.

51. U.S. Department of Housing and Urban Development. Conceptualizing and Measuring Resilience. [Internet] [Winter 2012; citied 2016]. https://www.huduser.gov/portal/periodicals/em/winter12/highlight2.html 
52. Beatley, T. (2014). Planning for Resilient Coastal Communities: Emerging Practice and Future Directions. Adapting to Climate Change. Springer Netherlands, 123-144.

53. Oliver-Smith, A., Cutter, L. S., Warner, K., Corendea, C., \& Yuzva, K. (2012). Addressing loss and damage in the context of social vulnerability and resilience. UNU-EHS.

54. Ross, A. D. (2013). Local disaster resilience: Administrative and political perspectives (Vol. 9). Routledge.

55. Kapucu, N., Hawkins C.V., Rivera F.I. (2013).Disaster resiliency: interdisciplinary perspectives. Routledge, Nature. 413 pages.

56. Frazier, T. G. (2012). Selection of scale in vulnerability and resilience assessments. J Geogr Nat Disasters, 2, 108.

57. N. Lam, N. S., Reams, M., Li, K., Li, C., \& Mata, L. P. (2015). Measuring Community Resilience to Coastal Hazards along the Northern Gulf of Mexico. Natural Hazards Review, 04015013.

58. Jenkins, S., and Jenkins, S. (2015). Resilience: The New Paradigm in Disaster Management-An Australian Perspective. World Journal of Engineering and Technology, 3(03), 129.

59. Yeletaysi, S., Ozceylan, D., Fiedrich, F., Harrald, J. R., \& Jefferson, T. (2009, June). A framework to integrate social vulnerability into catastrophic natural disaster preparedness planning. In The International Emergency Management Society-TIEMS 16th Annual Conference (pp. 9-11).

60. Pflicke, K. M., Greenberg, M., Whytlaw, J., Herb, J., \& Kaplan, M. (2015). Populations Vulnerable to Climate Change in New Jersey: Update of a Statistical Analysis. [Internet] [cited

http://research.fit.edu/sealevelriselibrary/documents/doc_mgr/443/Pficke\%20et\%20al.\%2 02015.\%20Populations\%20Vulnerable\%20to\%20CC.pdf

61. Glynn County, G. Social vulnerability and local hazard mitigation planning: Application and evaluation of a "SoVI-Lite" approach for.[Internet] [2015; cited 2016] https://www.researchgate.net/publication/270396734_Assessing_Social_Vulnerability_using_So VI-Lite A Demonstration Study at Glynn County GA

62. Office of Emergency Preparedness and Response. Vulnerable Populations: A FunctionBased Vulnerability Measure for the New York City Region. New York City Department 
of Health and Mental Hygiene [Internet][August 2013; cited 2016] http://www1.nyc.gov/assets/doh/downloads/pdf/em/regional hazards vulnerability measures.pdf

63. Mukhopadhyay S.. Environmental public health tracking ASTHO fellowship report. Tennessee Department of Health [Internet] [June 2013; cited 2016] http://www.astho.org/Programs/Environmental-Health/Tracking-Environmental-HealthHazards/EPHT-State-to-State-Peer-Fellowship-Program/Lead-Poisoning-and-SocialVulnerability-Index-Data-in-Tennessee/

64. Cutter, S. L. The landscape of disaster resilience indicators in the USA. Natural Hazards, 2016;80(2),741-758. 


\section{Appendix:}

\section{Validating Resilience and Vulnerability Indices in the Context of Natural Disasters}

\section{A. Index Metrics}

In this section, we present the full set of metrics included in each of the five indices we examine.

\section{A.1 BRIC Metrics}

The following 36 metrics, across five capitals, are used to calculate the BRIC index:

Social Resilience: Educational equity, Age, Transportation Access, Communication competency, Special needs, Health Coverage.

Economic Resilience: Housing capital, Employment (x2), Income and equality, Single sector employment dependence, Health Access.

Institutional Resilience: Mitigation (x3), Flood coverage, Municipal services, Political fragmentation, Previous disaster experience, Social connectivity.

Infrastructure Resilience: Housing type, Shelter capacity, Medical capacity, Access/evacuation potential, Housing age, Sheltering needs, Recovery.

Community Capital: Place attachment (x2), Political engagement, Religion, Civic involvement, Advocacy, Innovation.

\section{A.2 CDRI Metrics}

The following 75 metrics, across four capital indicators, are used to calculate the CDRI index. Note that the CDRI index also categorizes each metric across four disaster phase stages.

Social Capital: Nonprofit organizations, Recreational centers, Registered voters, Civic and political organizations, Census response rates, Religious organizations, Owner-occupied housing units, Professional associations, Business associations.

Economic Capital: Per capita income, Median household income, Employed civilian population, Median housing value, Business establishments, Population with health insurance.

Physical Capital: Building construction establishments, Heavy and civil engineering establishments, Highway construction establishments, Architecture establishments, Land subdivision establishments, Legal services establishments, Insurance establishments, Building inspection establishments, Landscape architecture establishments, Environmental consulting establishments, Environment and conservation establishments, Scientific research establishments, Universities, Housing Units, Vacant housing units, Hospitals, Hospital beds, Ambulances, Fire stations, Nursing homes, Hotels/motels, Occupied housing units with vehicle available, Special need transportation services, School and employee buses, Owner-occupied housing units with telephone service, Newspaper publishers, Radio stations, Television broadcasting, Internet service providers, Temporary shelters, Community housing, Community food service facilities, Schools, Licensed child care facilities, Utility systems construction establishments.

Human Capital: High school educated, Physicians, Health care support workers, Building construction workers, Heavy and civil engineering construction workers, Architecture and engineering workers, Environmental consulting workers, Environment and conser4vation workers, Land subdivision workers, Building inspectors, Landscape architects and planners, Property and causality insurance workers, Highway construction workers, Population employed in legal services, $\%$ population covered by comprehensive plan, $\%$ population covered by zoning regulations, \% population covered by building codes, \% population covered by FEMA approved 
mitigation plan, Community rating system scores, Fire fighters/prevention/law enforcement workers, Population employed in research and development services, University employees, Population that speaks English very well, Population employed in special need transportation services, Community/social workers.

\section{A.3 RCI Metrics}

The following 12 metrics, across three capacities, are used to calculate the RCI index:

Regional Economic Capacity: Income Equality, Economic Diversification, Regional Affordability, Business Environment.

Socio-Demographic Capacity: Educational Attainment, Without Disability, Out of Poverty, Health-Insured.

Community Connectivity Capacity: Civic Infrastructure, Metropolitan Stability, Homeownership, Voter participation.

\section{A.4 SoVI Metrics}

The following 11 metrics, ordered by percent of most to least variation explained, are used to calculate the SoVI index:

Personal wealth, Age, Density of the built environment, Single-sector economic dependence, Housing stock and tenancy, Race (African American), Ethnicity (Hispanic), Ethnicity (Native American), Race (Asian), Occupation, Infrastructure dependence.

\section{A.5 SVI Metrics}

The following 15 metrics, across four domains, are using to calculate the SVI index:

Socioeconomic Status: Percent individuals below poverty, Percent civilian unemployed, Per capita income, Percent persons with no high school diploma.

Household Composition/Disability: Percent persons 65 years of age or older, Percent persons 17 years of age or younger, Percent persons more than 5 years old with a disability, Percent male or female householder with no spouse and with children under 18.

Minority Status/Language: Percent minority, Percent persons 5 years of age or older who speak English less than "well".

Housing/Transportation: Percent multi-unit structure, Percent mobile homes, Crowding, No vehicle available, Percent of persons in group quarters.

\section{B. Results Within Shared Index Geographies}

In this section, we present correlation and regression results using only observations from the geographic intersection of all five indices. This geographic intersection is 14 counties across Alabama, Florida, and Mississippi, limited by the spatial scales of BRIC, CDRI, and RCI. Our intent is to test each index using the full geographic extent for which it was created and testing each index against the null hypothesis that the index does not explain the outcomes of interest. However, we also present these results that directly compare each index across the same geography. The results are briefly discussed below.

Table A displays the disaster index correlation coefficients across the intersecting geographic extents. When we restrict attention to the 14 counties in common between all five indices, the correlation coefficients are different both in magnitude as well as, in some cases, sign. Only 
BRIC/CDRI, SVI/CDRI, and SVI/RCI correlation remain the expected correlation sign. These results reflect how, across larger spatial scales, these indices may tend together, but across individual counties, each index may estimate very different levels of resilience or vulnerability.

Table A: Disaster Index Correlations Across the Intersecting Geographic Extents

\begin{tabular}{|c|c|c|c|c|c|}
\hline & BRIC & CDRI & $\mathrm{RCl}$ & SoVI & SVI \\
\hline BRIC & - & - & - & - & - \\
\hline CDRI & 0.3532 & - & - & - & - \\
\hline $\mathrm{RCl}$ & -0.0288 & -0.0647 & - & - & - \\
\hline SoVI & -0.5471 & -0.0245 & 0.4864 & & - \\
\hline SVI & 0.0858 & -0.7099 & -0.1553 & -0.2336 & - \\
\hline
\end{tabular}


Table B displays damages regression results identical to Table V in our paper, but with our sample restricted to the 14 common counties across disaster indices. While the magnitudes of the estimated coefficients change, as is to be expected with attention to a different spatial scale, we find the sign and statistical significance of each variable remains the same, except for RCI, which has altered signs and is now inconsistent with the theoretical sign. Therefore, even across this geographic scale, the performance of each individual index holds for damages.

Table B: Damage Functions with Disaster Indices Across 14 Counties

\begin{tabular}{|c|c|c|c|c|c|}
\hline VARIABLES & $\begin{array}{c}(1) \\
\text { Ln Damages }\end{array}$ & $\begin{array}{c}(2) \\
\text { Ln Damages }\end{array}$ & $\begin{array}{c}\text { (3) } \\
\text { Ln Damages }\end{array}$ & $\begin{array}{c}(4) \\
\text { Ln Damages }\end{array}$ & $\begin{array}{c}5) \\
\text { Ln Damages }\end{array}$ \\
\hline BRIC & $\begin{array}{c}3.040 * * * \\
(0.998)\end{array}$ & & & & \\
\hline CDRI & & $\begin{array}{c}-0.908^{* * *} \\
(0.173)\end{array}$ & & & \\
\hline $\mathrm{RCl}$ & & & $\begin{array}{c}2.546 * * * \\
(0.301)\end{array}$ & & \\
\hline SoVI & & & & $\begin{array}{c}0.333^{* * *} \\
(0.0890)\end{array}$ & \\
\hline SVI & & & & & $\begin{array}{c}0.440 * * * \\
(0.117)\end{array}$ \\
\hline Ln Risk Rate & $\begin{array}{c}-1.120 * * * \\
(0.222)\end{array}$ & $\begin{array}{l}-0.244 \\
(0.155)\end{array}$ & $\begin{array}{l}0.313^{*} \\
(0.183)\end{array}$ & $\begin{array}{l}0.0572 \\
(0.228)\end{array}$ & $\begin{array}{c}-0.492^{* * *} \\
(0.146)\end{array}$ \\
\hline Ln Magnitude & $\begin{array}{c}0.893^{* *} \\
(0.387)\end{array}$ & $\begin{array}{l}1.000^{* *} \\
(0.411)\end{array}$ & $\begin{array}{c}0.988^{* *} \\
(0.386)\end{array}$ & $\begin{array}{c}0.985^{* *} \\
(0.416)\end{array}$ & $\begin{array}{c}0.973 * * \\
(0.414)\end{array}$ \\
\hline Ln Capital Stock & $\begin{array}{c}0.468 * * * \\
(0.132)\end{array}$ & $\begin{array}{c}0.638^{* * *} \\
(0.120)\end{array}$ & $\begin{array}{c}0.381^{* * *} \\
(0.116)\end{array}$ & $\begin{array}{c}0.454 * * * \\
(0.120)\end{array}$ & $\begin{array}{c}0.531^{* * *} \\
(0.117)\end{array}$ \\
\hline Constant & $\begin{array}{l}-4.723^{*} \\
(2.692)\end{array}$ & $\begin{array}{l}-4.193 \\
(2.984)\end{array}$ & $\begin{array}{l}-0.694 \\
(2.726)\end{array}$ & $\begin{array}{l}-1.343 \\
(2.784)\end{array}$ & $\begin{array}{l}-3.970 \\
(3.017)\end{array}$ \\
\hline Observations & 583 & 583 & 579 & 583 & 583 \\
\hline R-squared & 0.087 & 0.104 & 0.148 & 0.081 & 0.087 \\
\hline
\end{tabular}

Robust standard errors in parentheses

$* * * p<0.01, * * p<0.05, * p<0.1$ 
Table $\mathrm{C}$ presents the regression results for the fatalities functions restricting attention to the counties shared by each disaster index. Similar to the damage results, we find that each index continues to perform with the same sign and statistical significance of the full sample results. These results give us confidence in the consistent performance of each index. We note that the magnitudes of the estimated coefficients change, as the restricted index sample will have different mean and variance than the full sample.

Table C: Fatalities Functions with Disaster Indices Across 14 Counties

\begin{tabular}{|c|c|c|c|c|c|}
\hline VARIABLES & $\begin{array}{c}(1) \\
\text { Fatalities }\end{array}$ & $\begin{array}{c}(2) \\
\text { Fatalities }\end{array}$ & $\begin{array}{c}(3) \\
\text { Fatalities }\end{array}$ & $\begin{array}{c}(4) \\
\text { Fatalities }\end{array}$ & $\begin{array}{c}(5) \\
\text { Fatalities }\end{array}$ \\
\hline BRIC & $\begin{array}{l}-2.545^{*} \\
(1.465)\end{array}$ & & & & \\
\hline CDRI & & $\begin{array}{c}-2.082^{* * *} \\
(0.808)\end{array}$ & & & \\
\hline $\mathrm{RCl}$ & & & $\begin{array}{c}-3.468 * * \\
(1.437)\end{array}$ & & \\
\hline SoVI & & & & $\begin{array}{l}0.0565 \\
(0.162)\end{array}$ & \\
\hline SVI & & & & & $\begin{array}{c}0.973^{* *} \\
(0.465)\end{array}$ \\
\hline Ln Risk Rate & $\begin{array}{l}-0.337 \\
(0.247)\end{array}$ & $\begin{array}{c}-0.493^{* *} \\
(0.237)\end{array}$ & $\begin{array}{c}-0.0281 \\
(0.0818)\end{array}$ & $\begin{array}{c}-0.550 \\
(0.346)\end{array}$ & $\begin{array}{c}-0.655^{* *} \\
(0.316)\end{array}$ \\
\hline Ln Avg. Population Density & $\begin{array}{l}-0.247 \\
(0.199)\end{array}$ & $\begin{array}{c}-0.353^{* *} \\
(0.157)\end{array}$ & $\begin{array}{c}-0.213 \\
(0.141)\end{array}$ & $\begin{array}{c}-0.520^{* *} \\
(0.256)\end{array}$ & $\begin{array}{c}-0.590 * * \\
(0.235)\end{array}$ \\
\hline Constant & $\begin{array}{c}9.704^{* *} \\
(4.561)\end{array}$ & $\begin{array}{c}4.638^{* *} \\
(1.891)\end{array}$ & $\begin{array}{l}1.456^{*} \\
(0.876)\end{array}$ & $\begin{array}{l}4.899 * \\
(2.511)\end{array}$ & $\begin{array}{l}-1.351 \\
(1.399)\end{array}$ \\
\hline Observations & 121 & 121 & 119 & 121 & 121 \\
\hline
\end{tabular}

Robust standard errors in parentheses

$* * * p<0.01, * * p<0.05, * p<0.1$ 
Table C presents the regression results for our disaster declaration functions across the geographically restricted sample. We note that the sample size, at 14 , is too small to draw any conclusions from the results and none of the estimated index coefficients are statistically significant. However, we note that of the three indices that had statistically significant coefficients in Table VII in our main results (BRIC, SoVI, and SVI), they have maintained the same coefficient sign in these regressions. Therefore, these restricted sample results remain consistent with our main results.

Table D: Disaster Declaration Functions with Disaster Indices Across 14 Counties

\begin{tabular}{|c|c|c|c|c|c|}
\hline VARIABLES & $\begin{array}{c}\text { (1) } \\
\text { Ln Disaster } \\
\text { Declarations }\end{array}$ & $\begin{array}{c}\text { (2) } \\
\text { Ln Disaster } \\
\text { Declarations }\end{array}$ & $\begin{array}{c}\text { (3) } \\
\text { Ln Disaster } \\
\text { Declarations } \\
\end{array}$ & $\begin{array}{c}\text { (4) } \\
\text { Ln Disaster } \\
\text { Declarations }\end{array}$ & $\begin{array}{c}\text { (5) } \\
\text { Ln Disaster } \\
\text { Declarations }\end{array}$ \\
\hline BRIC & $\begin{array}{c}0.517 \\
(0.627)\end{array}$ & & & & \\
\hline CDRI & & $\begin{array}{c}0.242 \\
(0.156)\end{array}$ & & & \\
\hline $\mathrm{RCl}$ & & & $\begin{array}{l}-0.0686 \\
(0.342)\end{array}$ & & \\
\hline SoVI & & & & $\begin{array}{c}0.0997 \\
(0.0707)\end{array}$ & \\
\hline SVI & & & & & $\begin{array}{l}-0.0755 \\
(0.100)\end{array}$ \\
\hline Ln Risk Rate & $\begin{array}{l}-0.152 \\
(0.175)\end{array}$ & $\begin{array}{l}-0.0554 \\
(0.131)\end{array}$ & $\begin{array}{l}-0.0813 \\
(0.200)\end{array}$ & $\begin{array}{c}0.200 \\
(0.232)\end{array}$ & $\begin{array}{l}-0.0297 \\
(0.150)\end{array}$ \\
\hline Ln Avg. Population Density & $\begin{array}{l}-0.112 \\
(0.124)\end{array}$ & $\begin{array}{c}-0.119 \\
(0.113)\end{array}$ & $\begin{array}{r}-0.0775 \\
(0.136)\end{array}$ & $\begin{array}{l}-0.148 \\
(0.121)\end{array}$ & $\begin{array}{c}-0.0941 \\
(0.121)\end{array}$ \\
\hline Constant & $\begin{array}{l}2.398^{*} \\
(1.189)\end{array}$ & $\begin{array}{c}3.262 * * * \\
(0.572)\end{array}$ & $\begin{array}{c}3.256^{* * *} \\
(0.756)\end{array}$ & $\begin{array}{c}2.429 * * \\
(0.816)\end{array}$ & $\begin{array}{c}3.642 * * * \\
(0.820)\end{array}$ \\
\hline Observations & 14 & 14 & 13 & 14 & 14 \\
\hline R-squared & 0.183 & 0.296 & 0.115 & 0.272 & 0.174 \\
\hline
\end{tabular}

Robust standard errors in parentheses

*** $p<0.01,{ }^{* *} p<0.05, * p<0.1$ 